Proc. Indian Acad. Sci. (Chem. Sci.), Vol. 96, No. 6, April 1986, pp. 419-448.

(C) Printed in India.

\title{
Oxides with a tunnel structure characterized by a mixed framework of octahedra and tetrahedra
}

\author{
B RAVEAU \\ Laboratoire de Cristallographie, Chimie et Physique des Solides, Equipe Oxyde, U.A. 251, \\ ISMRa-Université, 14032 Caen Cedex, France \\ Abstract. Oxides with a three-dimensional mixed framework built up from octahedra and \\ tetrahedra are attractive owing to the possibility of forming large tunnels which can intersect as \\ in the ionic conductors, or also to build anisotropic electronic conductors. The structural \\ relationships between these oxides are analyzed here. Three classes of oxides are mainly \\ studied here: mixed frameworks with tetrahedral silicate and germanate groups, oxides in \\ which tetrahedral phosphates are involved and compounds inyolying silicophosphate groups. \\ Other examples of mixed frameworks such as those involving $\mathrm{GaO}_{4}$ tetrahedra and $\mathrm{NbO}_{*}$ \\ tetrahedra are also described.
}

Keywords. Mixed framework oxides; tunnel structure oxides; non-stoichiometric oxides.

\section{Introduction}

The properties of oxides characterized by a tunnel structure may be drastically influenced by the nature of their framework. For instance, the widest tunnels are observed for tetrahedral oxides: the zeolites are well known for their ion exchange properties and especially for their catalytic properties. On the other hand, octahedral oxides exhibit much smaller tunnels, but they offer the possibility of obtaining various physical properties; for instance the oxygen bronzes are known for their electron transport properties whereas bronzoids can be obtained which are ferroelectric or ionic conductors. In this respect, the synthesis of oxides with a mixed framework of octahedra and tetrahedra is attractive. Nevertheless, the number of these oxides is limited, owing to the weak ability of octahedra and tetrahedra to adapt to each other. The present review deals with the study of such frameworks. Mixed valence oxides resulting from the creation of anionic vacancies in an octahedral framework, such as oxygen-deficient perovskites will not be discussed here. Thus, the 'true' 'mixed frameworks' will be mainly built by association of $\mathrm{SiO}_{4}, \mathrm{GeO}_{4}, \mathrm{PO}_{4}, \mathrm{NbO}_{4}, \mathrm{MoO}_{4}$ and $\mathrm{GaO}_{4}$ tetrahedra with $\mathrm{MO}_{6}$ octahedra, $M$ being a transition element.

2. Mixed frameworks with tetrahedral 'silicate' and 'germanate' groups (Roedder 1951; Myashiro 1956; Robbins and Levin 1961; Gross et al 1965; Seifert and Schreyer 1967, 1969; Blasse and Bril 1970; Olsen and Bunch 1970; Shannon and Katz 1970; Choisnet et al 1972, 1976, 1977; Puscharovskii et al 1972; Evans et al 1973; Goreaud et al 1973; Groult et al 1976; Nguyen et al 1976, 1980; Chailleux et al 1978; Shannon et al 1978; Studer and Raveau 1978; Raveau 1979).

The great rigidity of the $\mathrm{SiO}_{4}$ and $\mathrm{GeO}_{4}$ tetrahedra makes for few oxides with a 
tunnel structure built up from $\mathrm{SiO}_{4}$ (or $\mathrm{GeO}_{4}$ ) tetrahedra and $\mathrm{MO}_{6}$ octahedra are known. Moreover most of the them are richer in the tetrahedral element than in the octahedral one. The oxides $A_{6-x} M_{6} \mathrm{Si}_{4} \mathrm{O}_{26}$ and $A_{6-x} M_{6} \mathrm{Ge}_{4} \mathrm{O}_{26}$ are the only ones which correspond to a ratio $M / S i$ greater than one. Even for molar ratios $M / S i$,
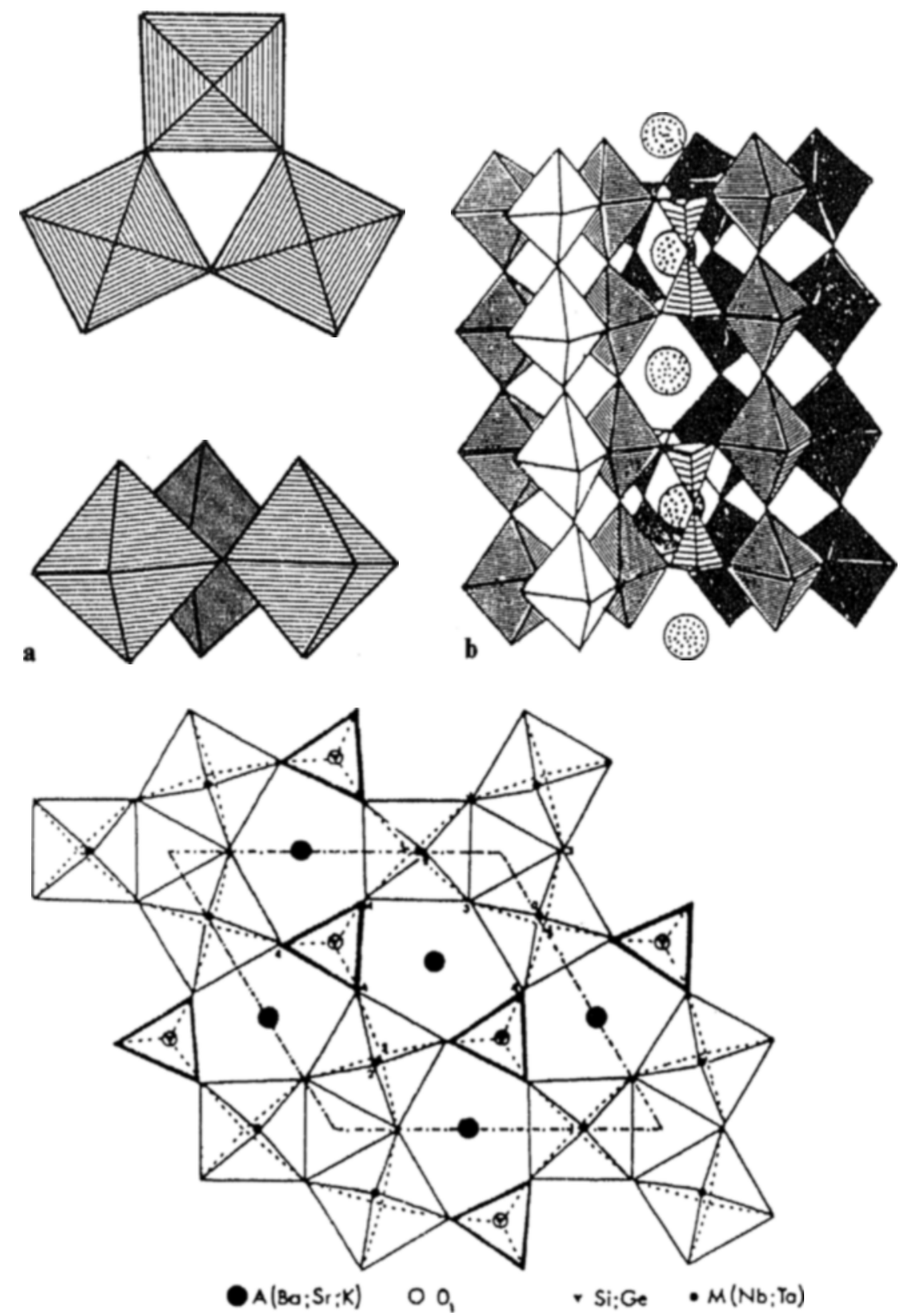

Figure 1. The siliconiobate and tantalate $A_{3} M_{6} \mathrm{Si}_{4} \mathrm{O}_{26}$ and $\mathrm{K}_{6-2 \times} \mathrm{Ba}_{x} \mathrm{Ta}_{6} \mathrm{Si}_{4} \mathrm{O}_{36}$. (a) the octahedral units $\mathrm{M}_{3} \mathrm{O}_{15}$, (b) the triple files of octahedra and the $\mathrm{Si}_{2} \mathrm{O}_{7}$ groups, (c) projection of the structure on to the $(001)$ plane. 
smaller than one, few oxides with a tunnel structure are known; three examples will be described here: the benitoïtes $A M \mathrm{Si}_{3} \mathrm{O}_{9}$ and $A M \mathrm{Ge}_{3} \mathrm{O}_{9}$, the milarites $A_{x} M_{3} M_{2}^{\prime} \mathrm{Si}_{12} \mathrm{O}_{30}$ and the silicates $\mathrm{Na}_{5} M \mathrm{Si}_{4} \mathrm{O}_{12}$.

The siliconiobates and tantalates $A_{3} M_{6} \mathrm{Si}_{4} \mathrm{O}_{26}(A=\mathrm{Ba}, \mathrm{Cr}, M=\mathrm{Ta}, \mathrm{Nb})$ $\mathrm{K}_{6-x} \mathrm{Ba}_{x} \mathrm{Ta}_{6} \mathrm{Si}_{4} \mathrm{O}_{26}$ and the silicogermanates $\mathrm{K}_{6} M_{6} \mathrm{Si}_{4-x} \mathrm{Ge}_{x} \mathrm{O}_{26}(M=\mathrm{Ta}, \mathrm{Nb})$ form an important family of tunnel structures. In these hexagonal oxides the $M_{6} \mathrm{Si}_{4} \mathrm{O}_{26}$ framework is built up from octahedral units ' $M_{3} \mathrm{O}_{15}$ ' (figure la) and disilicate groups sharing their corners. Along $c$ the octahedral units ' $M_{3} \mathrm{O}_{15}$ ' share their corners, forming infinite triple files of octahedra (figure 1b) identical to those observed in the hexagonal tungsten bronze structure ( $\mathrm{T}$ (B); laterally, in the (001) plane the octahedral files share their corners with $\mathrm{Si}_{2} \mathrm{O}_{7}$ (or $\mathrm{Ge}_{2} \mathrm{O}_{7}$ ) groups whose ternary axis is parallel to $c$ (figure 1c). This host lattice forms pentagonal tunnels very similar to those observed for the tetragonal tungsten bronze and characterized by angles of $90^{\circ}$ and $120^{\circ}$. In these tunnels the $\mathrm{K}^{+}$and $\mathrm{Ba}^{2+}$ ions are located at two different levels along $c$ (figure $1 \mathrm{~b}$ ); the difference between these two sites is due to the presence in one of them of the bridging oxygen of the $\mathrm{Si}_{2} \mathrm{O}_{7}$ group at the same level; consequently two sorts of coordinations are observed for the $A$ ions $(10+3)$ and $(10+5)$. The important deviation from stoichiometry on the $A$ cations, with $x$ values ranging from 0 to 3 , is another common point with the Tтв structure. The boroniobate and tantalate $\mathrm{KM}_{3} \mathrm{~B}_{2} \mathrm{O}_{12}(M=\mathrm{Ta}, \mathrm{Nb})$ have got a very similar framework, in spite of their different formation. This latter structure is simply deduced from the $M_{6} \mathrm{Si}_{4} \mathrm{O}_{26}$ framework by replacing each disilicate group by two triangular $\mathrm{BO}_{3}$ groups, which ensure the cohesion between the octahedral files. Thus the $M_{6} \mathrm{~B}_{4} \mathrm{O}_{24}$ framework (figure 2) is very similar to the one of $\mathrm{K}_{6} M_{6} \mathrm{Si}_{4} \mathrm{O}_{26}$. The great flexibility of such a structure is confirmed by its possible intergrowth with the hexagonal oxide $A_{3} M_{8} \mathrm{O}_{21}(A=\mathrm{Ba}, \mathrm{Sr}, \mathrm{K} ; M=\mathrm{Nb}, \mathrm{Ta}$, Ti). This latter oxide represented by the composition $\mathrm{Ba}_{3} \mathrm{Nb}_{4} \mathrm{Ti}_{4} \mathrm{O}_{21}$, has its octahedral framework formed of octahedral units $M_{6} \mathrm{O}_{24}$ resulting from the association of two ' $\mathrm{M}_{3} \mathrm{O}_{15}$ ' units by the edges of their octahedra (figure 3). Along $c$ the $M_{3} \mathrm{O}_{25}$ units share the corners of their octahedra forming infinite triple files of octahedra whereas in the (001) plane these files share their corners with octahedra whose ternary axis is parallel to $c$ (figure 4). Consequently, the (001) planes of both frameworks exhibit a bidimensional accord. This similarity between the two structures allows the building up of a series of intergrowths $\left(A_{6-x} M_{6} \mathrm{Si}_{4} \mathrm{O}_{26}\right)_{n} \cdot\left(A_{3} M_{8} \mathrm{O}_{21}\right)_{m}$ as shown on figure 5 which corresponds to $\mathrm{K}_{10} \mathrm{Nb}_{22} \mathrm{Ge}_{4} \mathrm{O}_{68}(n=1, m=2)$.

The numerous hexagonal silicates and germanates $A M \mathrm{Si}_{3} \mathrm{O}_{9}$ and $A M \mathrm{Ge}_{3} \mathrm{O}_{9}$

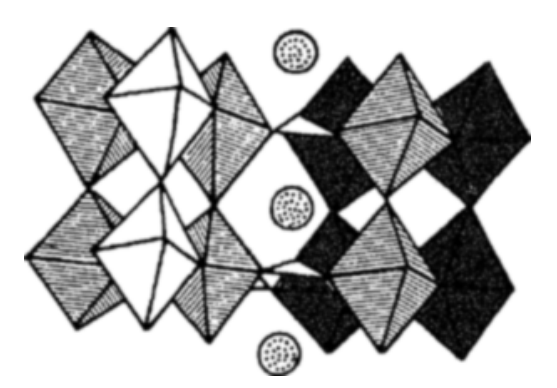

Figure 2. The boroniobate $\mathrm{K}_{3} \mathrm{Nb}_{3} \mathrm{~B}_{2} \mathrm{O}_{12}$ : the triple files of octahedra and their connection with the $\mathrm{BO}_{3}$ triangles. 

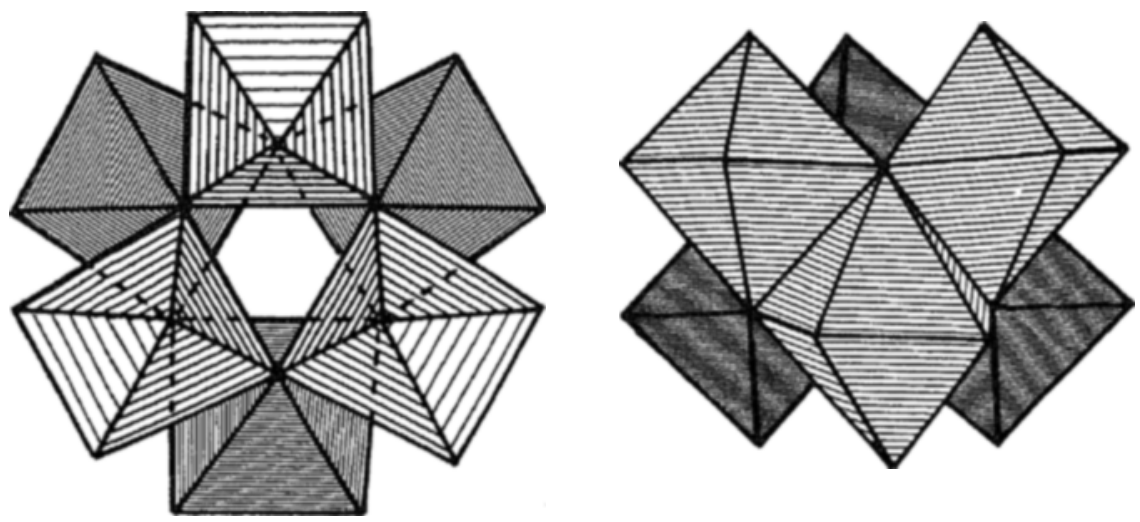

Figure 3. The structural unit ' $M_{6} \mathrm{O}_{24}$ ' resulting from theassociation of two ' $M_{3} \mathrm{O}_{15}$ ' units.

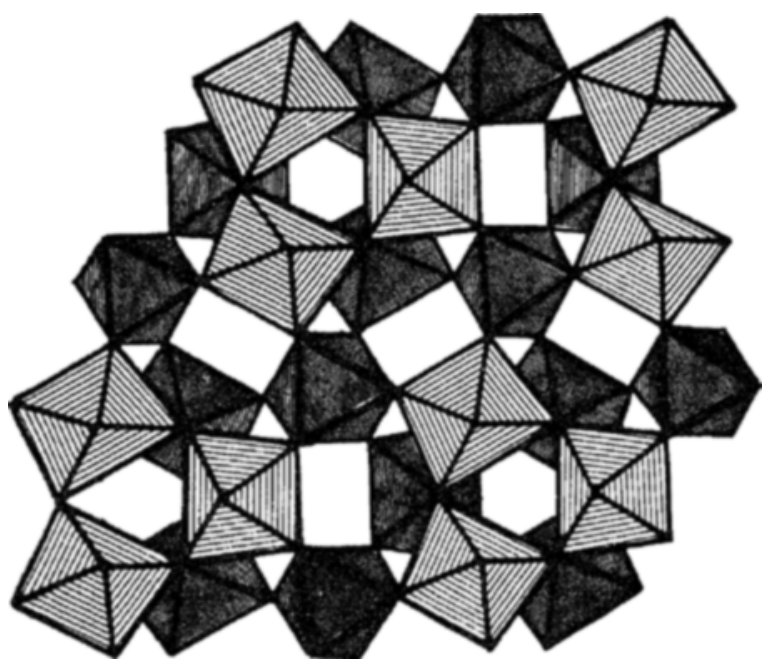

Figure 4. Projection of the structure of the hexagonal oxides $\mathrm{K}_{3} \mathrm{M}_{8} \mathrm{O}_{21}$ on to the $(001)$ plane.

( $A=\mathrm{K}, \mathrm{Rb}, \mathrm{Tl}, \mathrm{Ba} ; M=\mathrm{Ta}, \mathrm{Nb}, \mathrm{Sn}, \mathrm{Ti}$ ) belonging to the benitoite family result from the ability of $\mathrm{MO}_{6}$ octahedra to adopt a tetrahedral framework. Their framework is built up of $\mathrm{Si}_{3} \mathrm{O}_{9}\left(\mathrm{Ge}_{3} \mathrm{O}_{9}\right)$ rings which are linked through isolated $M \mathrm{O}_{6}$ octahedra (figure 6) forming wide tunnels where the $A$ ions are located. It must be pointed out that no deviation from stoichiometry has been observed for those oxides in spite of the presence of tunnels.

The silicates of the milarite family $A_{x} M_{3} M_{2}^{\prime} \mathrm{Si}_{12} \mathrm{O}_{30}(A=\mathrm{K}, \mathrm{Na}, \mathrm{Ba}, \mathrm{Rb} ; M=\mathrm{Zn}$, $\mathrm{Mn}, \mathrm{Al}, \mathrm{Te}, \mathrm{Cu}, \mathrm{Mg} ; \mathrm{M}^{\prime}=\mathrm{Mg}, \mathrm{Mn}, \mathrm{Fe}, \mathrm{Cu}, \mathrm{Li}$ ) exhibit variable insertion rates ranging from $x=1$ to $x=3$. In those hexagonal oxides, the framework is almost only tetrahedral. The $\mathrm{SiO}_{4}$ tetrahedra form hexagonal $\mathrm{Si}_{12} \mathrm{O}_{30}$ crowns (figure $7 \mathrm{a}$ ), connected through rings of $\mathrm{MO}_{4}$ tetrahedra and $\mathrm{M}^{\prime} \mathrm{O}_{6}$ octahedra. In those rings the $\mathrm{MO}_{4}$ tetrahedra and $M^{\prime} \mathrm{O}_{6}$ octahedra share their edges. The stacking of the $\mathrm{Si}_{12} \mathrm{O}_{30}$ crowns 


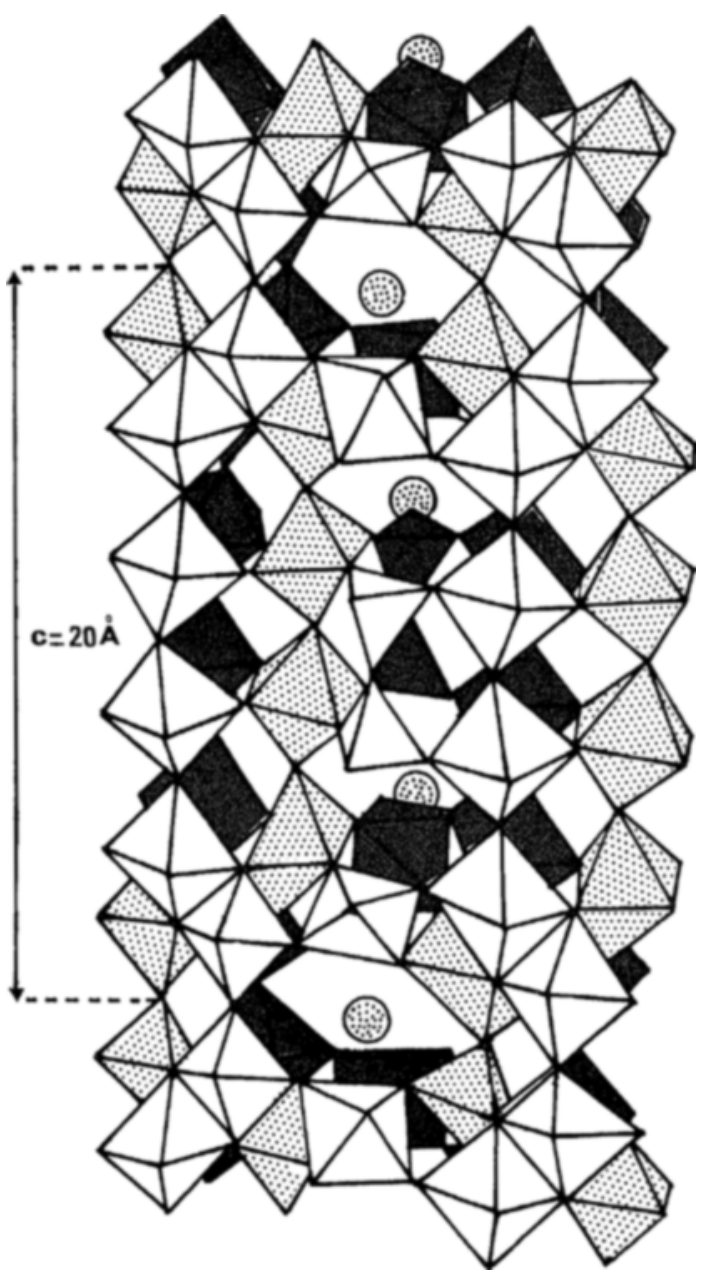

Figure 5. Structure of the oxide $\mathrm{K}_{10} \mathrm{Nb}_{22} \mathrm{Ge}_{4} \mathrm{O}_{68}$, the second member of the inter-growth $\left(A_{3} M_{8} \mathrm{O}_{21}\right) \cdot A_{6-x} M_{6} \mathrm{Ge}_{4} \mathrm{O}_{26}$.

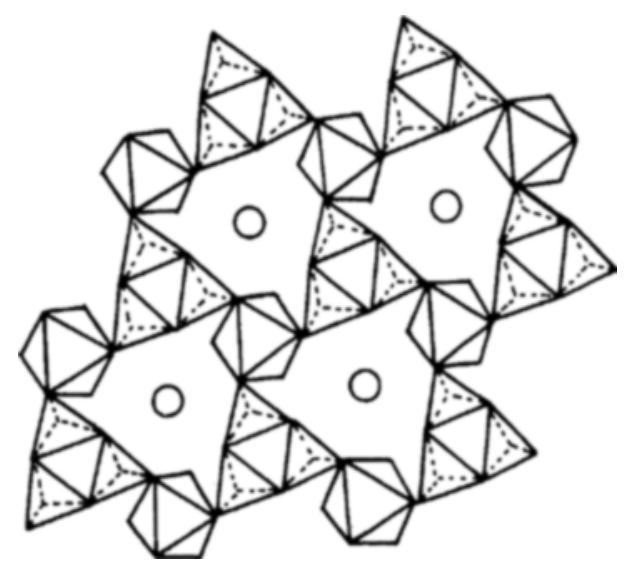

Figure 6. Projection of the structure of the benitoite $\mathrm{KNbSi}_{3} \mathrm{O}_{9}$ on to the (001) plane. 

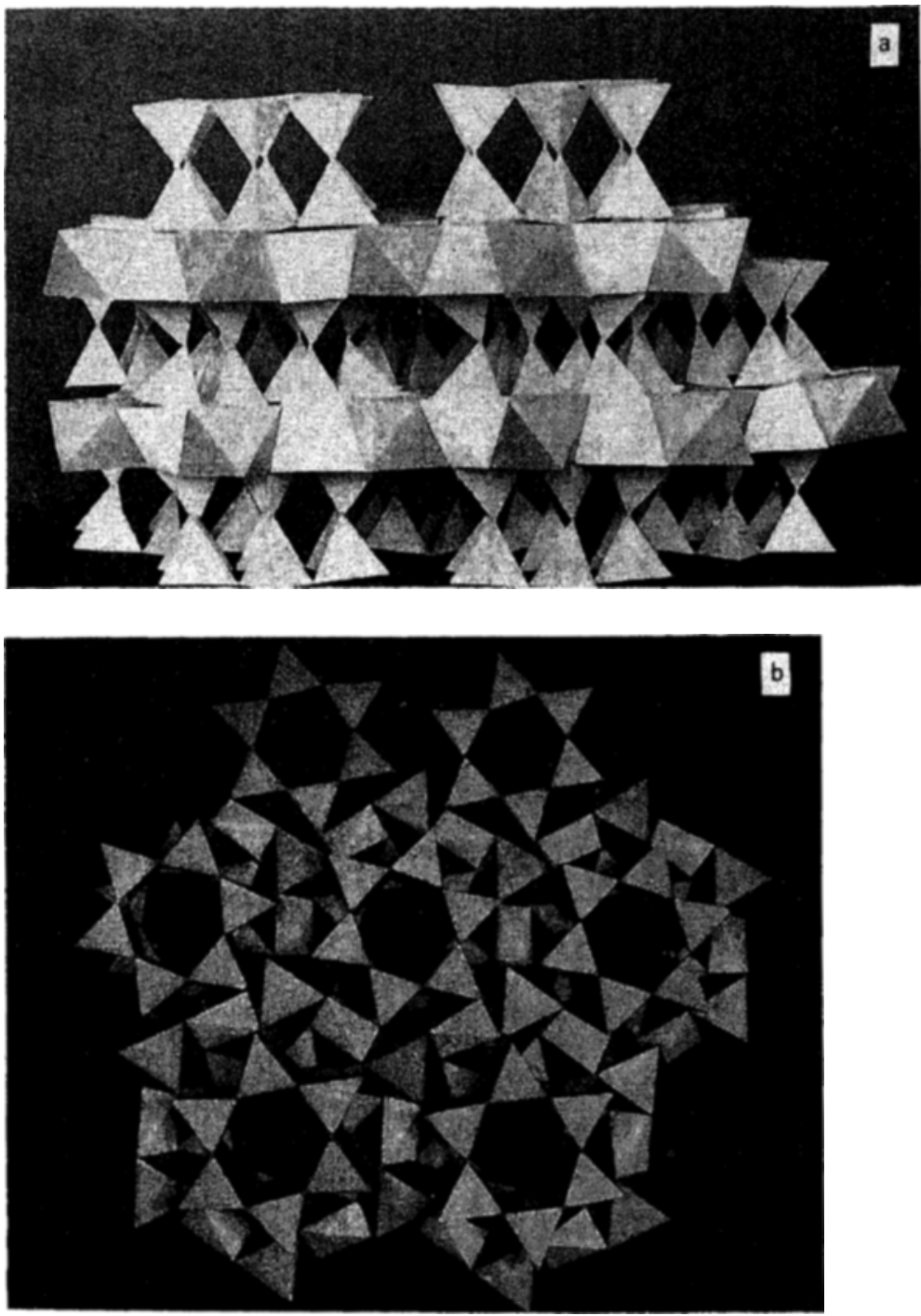

Figure 7. The milarite host-lattice $\mathrm{M}_{3} \mathrm{M}_{2}^{\prime} \mathrm{Si}_{12} \mathrm{O}_{30}$ : (a) view along the direction perpendicular to $c$, (b) view along $c$.

along $c$ delimits two sorts of tunnels, inside and outside of the crowns respectively, where the $A$ ions are located (figure $7 \mathrm{~b}$ ).

The important family of ionic conductors $\mathrm{Na}_{5} \mathrm{MSi}_{4} \mathrm{O}_{12}(M=\mathrm{Fe}$, In, Se, Y and $\mathrm{Ln}=\mathrm{Ln}$ to $\mathrm{Sm}$ ) are also characterized by a mainly tetrahedral framework. The host lattice of these oxides which is formed of tetrahedral rings $\mathrm{Si}_{12} \mathrm{O}_{30}$, connected through $\mathrm{MO}_{6}$ octahedra (figure 8) delimits two sorts of tunnels, inside and outside the rings respectively. It has been shown that the $\mathrm{Na}^{+}$ions located outside the rings are mobile contrary to those located inside. 


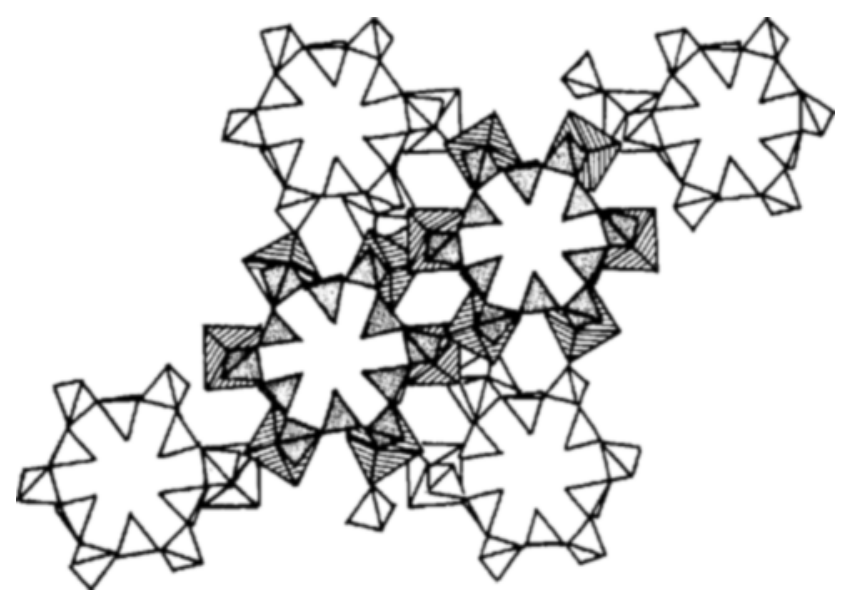

Figure 8. Projection of the structure of the ionic conductor $\mathrm{Na}_{5} \mathrm{MSi}_{4} \mathrm{O}_{12}$ on to the (001) plane.

3. Mixed frameworks with tetrahedral 'phosphate' groups (Magneli 1948; Kierkegaard 1962; Kihlborg 1963; Middlemis 1978; Giroult et al 1981, 1982; Domenges et al 1982, 1983, 1984, 1985; Hervieu and Raveau 1982, 1983; Labbe et al 1982; Leclaire et al 1983, 1985b; Benmoussa et al 1984; Goreaud et al 1985; Hervieu et al 1985; Masse et al 1985)

The $\mathrm{PO}_{4}$ tetrahedra seem to adapt octahedral frameworks much more easily than the $\mathrm{SiO}_{4}$ groups. Nevertheless the nature of $M$ ions of the octahedral lattice is important: most of the three-dimensional frameworks can be obtained by association of $\mathrm{PO}_{4}$ tetrahedra with $\mathrm{WO}_{6}, \mathrm{MoO}_{6}$ and $\mathrm{VO}_{6}$ octahedra.

The numerous family of phosphate tungsten bronzes can be considered as one of the most representative examples of adaptability of phosphate groups to an octahedral framework which is in fact that of $\mathrm{ReO}_{3}$. The relationships between the different series of phosphate tungsten bronzes can easily be understood by considering the great ability of the $\mathrm{PO}_{4}$ tetrahedron to replace an octahedron without changing the geometry of the $\mathrm{ReO}_{3}$-type framework. The starting point of the structural chemistry of these bronzes can be represented by layers of the $\mathrm{ReO}_{3}$-type which are one octahedron thick along $[001]_{\mathrm{ReO}}$ and $n$ octahedra wide along $[100]_{\mathrm{ReO}_{3}}$, bordered by simple $\mathrm{PO}_{4}$ tetrahedra along the latter direction (figure 9a). Two ways of association of these layers along the direction perpendicular to their mean plane can be considered. In the first one two adjacent identical layers are stacked in such a way that $\mathrm{WO}_{6}$ octahedra share their corners with other octahedra only, leading to the formation of diphosphate groups (figure $9 \mathrm{~b}$ ), whereas in the second manner two successive layers are stacked up by comer-sharing their polyhedra such that two tetrahedra belonging to two different layers are never connected (figure 9c). Thus, two sorts of slabs can be distinguished: $\mathrm{ReO}_{3}$-type slabs bordered with diphosphate groups which can also be represented by figure $9 \mathrm{a}$, and $\mathrm{ReO}_{3}$-type slabs bordered by simple $\mathrm{PO}_{4}$ tetrahedra stacked according to figure $9 \mathrm{c}$, leading to the scheme presented in figure $9 \mathrm{~d}$.

The lateral connection of the $\mathrm{ReO}_{3}$-type slabs bordered with diphosphate groups can be carried out in two different ways (figure 10 ) which differ from each other only by a 


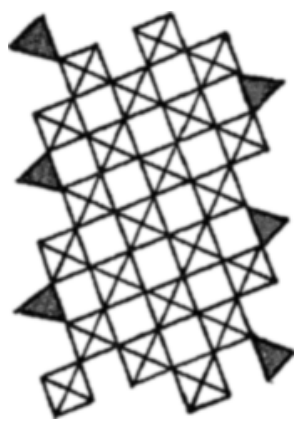

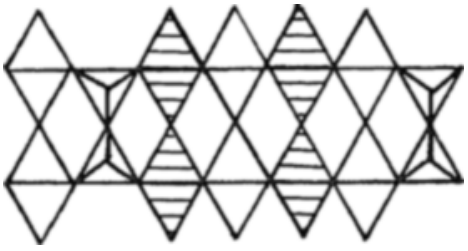

b

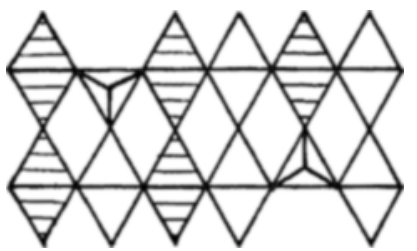

c

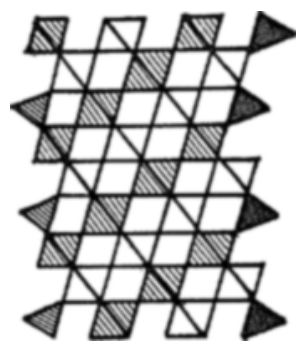

d

Figure 9. $\mathrm{ReO}_{3}$-type slabs of the phosphate bronzes bordered with (a) $\mathrm{PO}_{4}$ tetrahedra; their two ways of stacking leading to (b) diphosphate groups, and (c) single $\mathrm{PO}_{4}$ tetrahedra. (d) The other representation of the stacking according to (c).

rotation of $180^{\circ}$ of one layer out of two around the direction perpendicular to the slabs. This first type of association leads to the diphosphate tungsten bronze with hexagonal tunnels $\left(\mathrm{DPTB}_{\mathrm{H}}\right.$ ) (figure 10b) and to the diphosphate tungsten bronze with pentagonal tunnels (DPTB $)$ (figure 10c) respectively. The DPTB ${ }_{\mathrm{H}}, A_{x}\left(\mathrm{P}_{2} \mathrm{O}_{4}\right)_{2}\left(\mathrm{WO}_{3}\right)_{2 m}(A=\mathrm{K}, \mathrm{Rb}$, $\mathrm{Tl}, \mathrm{Ba}, x \sim 1)$, thus form an important family whose different $m$-members differ only by the number $m$ of octahedra which characterize the $\mathrm{ReO}_{3}$-type slab; the size of their hexagonal tunnels which are characterized by angles of $120^{\circ}$ and $90^{\circ}$, makes them comparable to the HTB. The DPTB $_{\mathrm{p}}$, whose composition may be formulated as $\left(\mathrm{P}_{2} \mathrm{O}_{4}\right)_{2}\left(\mathrm{WO}_{3}\right)_{2 m}$ or $\mathrm{K}_{x}\left(\mathrm{P}_{2} \mathrm{O}_{4}\right)_{2}\left(\mathrm{WO}_{3}\right)_{2 m}$, have never been isolated in the form of pure samples, but have been observed as microcrystals by high resolution electron microscopy. Semi-regular sequences are often observed involving diphosphate planes as shown by the micrograph of figure 11a; the structure of such junctions (figure 11b) forming pentagonal tunnels was confirmed by simulation (figure 11c).

The lateral connection of the $\mathrm{ReO}_{3}$-type slabs bordered with simple $\mathrm{PO}_{4}$ tetrahedra can also be connected in two different ways (figure 12) which differ also from each other only by the rotation of one slab out of two by $180^{\circ}$ around an axis perpendicular to the slabs. Consequently two monophosphate bronze families have been isolated: the monophosphate tungsten bronzes with pentagonal tunnels $\left(\mathrm{MPrB}_{\mathrm{p}}\right)\left(\mathrm{PO}_{2}\right)_{4}\left(\mathrm{WO}_{3}\right)_{2 m}$ (figure 12b) and the monophosphate tungsten bronzes with hexagonal tunnels $\left(\mathrm{MPTB}_{\mathrm{H}}\right)$, $A_{x}\left(\mathrm{PO}_{2}\right)_{4}\left(\mathrm{WO}_{3}\right)_{2 m}(A=\mathrm{Na}, \mathrm{K}, x=2)$ (figure $\left.12 \mathrm{c}\right)$; as for the DPTB series the different members of these series differ from one another only by the number $m$ of octahedra which determine the width of the $\mathrm{ReO}_{3}$-type slabs.

The great flexibility of such mixed frameworks are shown by the HREM study of the barium $\mathrm{DPTB}_{\mathrm{H}}$. For instance besides the perfect integral $m$-members (figure 13), one observes for non integral $m$-values intergrowths of different $m$-members (figure 14), and 


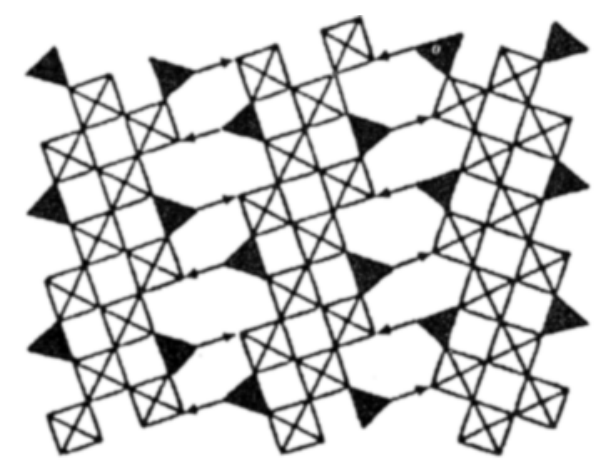

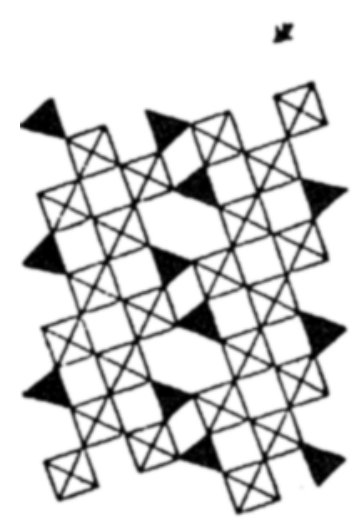

b

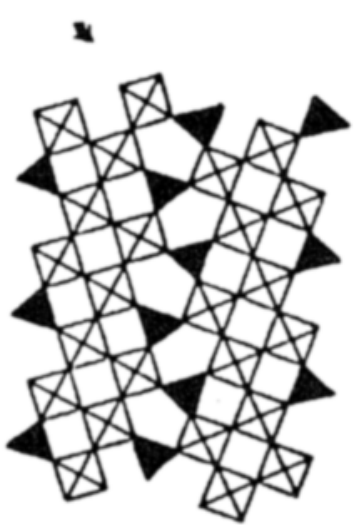

c

Figure 10. Lateral connection of the $\mathrm{ReO}_{3}$-type slabs bordered with (a) diphosphate groups, leading to the diphosphate tungsten bronzes with (b) hexagonal tunnels (DPTB $\mathrm{B}_{\mathrm{H}}$ ), and to (c) the diphosphate tungsten bronzes with pentagonal tunnels (DPTB ). $^{2}$

the possibility of stopping the propagation of the phosphate planes leading to wide $\mathrm{ReO}_{3}$-type regions (figure 15), or of shifting phosphate planes with respect to one another in two adjacent regions of a crystal (figure 16). It is worth noting that the presence of one diphosphate group in the $\mathrm{ReO}_{3}$ matrix leads to the formation of dislocations (figure 17). The adaptability of those mixed frameworks to the shear structures is also remarkable as shown from the regular lateral intergrowth of the $\{102\}$ C.S. planes with diphosphate planes (figure 18) and more complex associations of different shear planes with diphosphate planes as shown in figures 19 and 20 .

The great ability of the $\mathrm{WO}_{6}$ octahedra to be connected to $\mathrm{PO}_{4}$ tetrahedra to form a tunnel structure is also found in the oxides $\mathrm{P}_{8} \mathrm{~W}_{12} \mathrm{O}_{52}, \mathrm{CsP}_{8} \mathrm{~W}_{8} \mathrm{O}_{40}$ and $\mathrm{NaWPO}_{6}$. The host lattice of the oxide $\mathrm{P}_{8} \mathrm{~W}_{12} \mathrm{O}_{52}$ (figure 21) formed of ribbons of $\mathrm{ReO}_{3}$-type connected to $\mathrm{P}_{2} \mathrm{O}_{7}$ groups, shows that various tunnels-with a pentagonal and hexagonal section-can be empty as in $\mathrm{MPTB}_{\mathrm{P}}$. The bronze $\mathrm{CsP}_{8} \mathrm{~W}_{8} \mathrm{O}_{40}$ whose framework is built up from $\mathrm{ReO}_{3}$-type columns, connected through diphosphate groups is remarkable for its octogonal tunnels (figure 22) which are among the widest known in oxides with a mixed framework. Nevertheless no deviation from stoichiometry has 
been observed for the $\mathrm{Cs}^{+}$ion located in the tunnels of this latter oxide. In the same way the phosphotungstate $\mathrm{NaPWO}_{6}$ and the isomorphous oxide $\mathrm{NaPMoO}$, are stoichiometric in spite of the fact that they exhibit a tunnel structure. The host lattice of these compounds is characterized by infinite mixed chains in which one octahedron alternates with one $\mathrm{PO}_{4}$ tetrahedron (figure 23a); laterally these chains are linked together in such a way that every tetrahedron of one chain shares one corner with an octahedron of the adjacent chain forming an helicoidal arrangement of the polyhedra (figure 23b). The structure of the phosphomolybdates $\mathrm{PbMO}_{2} \mathrm{P}_{2} \mathrm{O}_{12}$ and
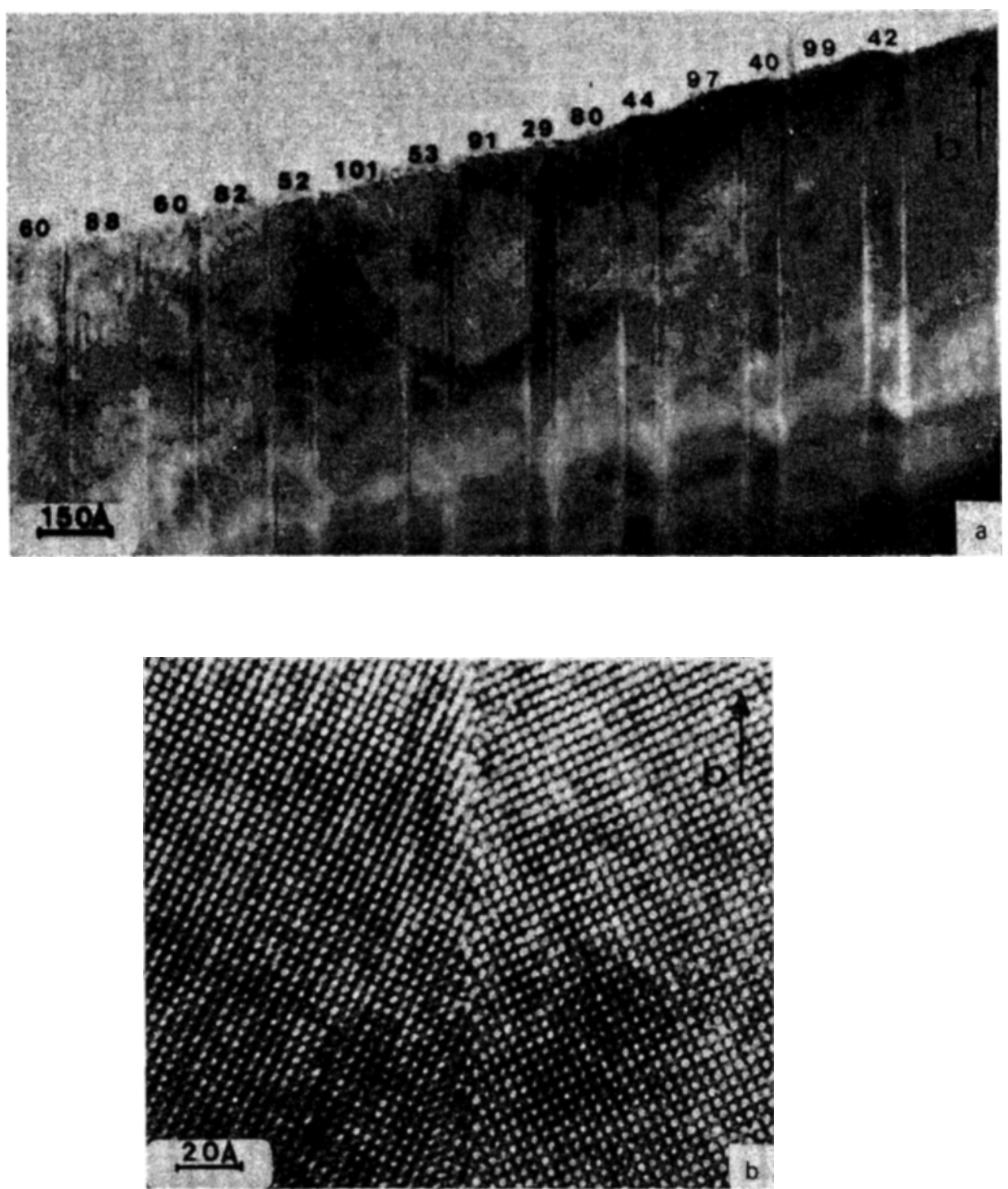

Figure 11. (a) and (b). 

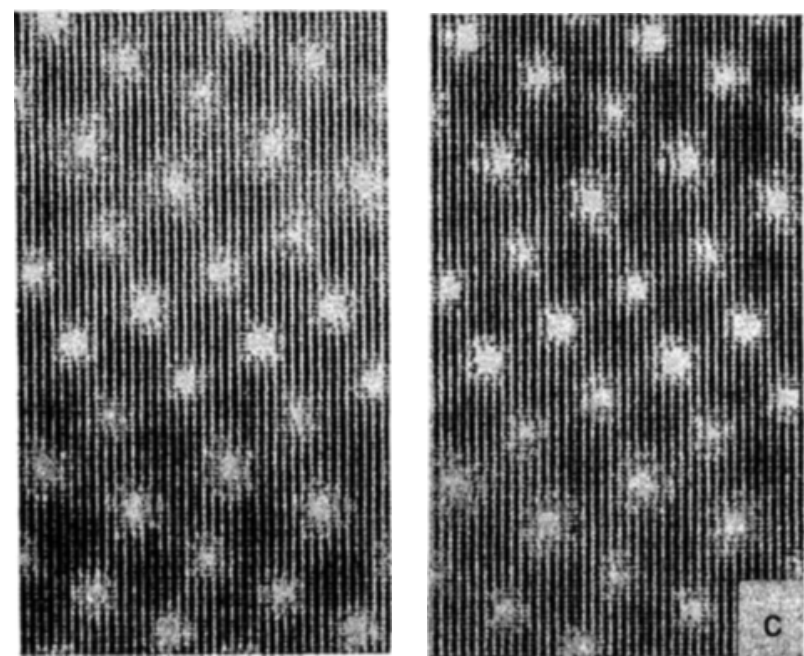

Figure 11 (c).

Figure 11. Diphosphate tungsten bronzes with pentagonal tunnels in the system $\left(\mathrm{P}_{2} \mathrm{O}_{4}\right)_{2}\left(\mathrm{WO}_{3}\right)_{2 m}$ : (a) low resolution image showing a regular distribution of $\mathrm{WO}_{3}$-slabs in the mean sequence 48.91 (b) HREM micrograph of the twin boundary in a $\left(\mathrm{P}_{2} \mathrm{O}_{4}\right)_{2}\left(\mathrm{WO}_{3}\right)_{2 m}$ crystal and (c) its fitness with the calculated image for a $-400 \AA$ defocus value.

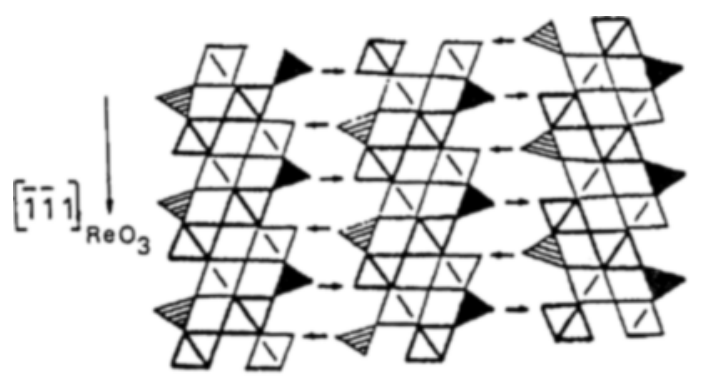

a

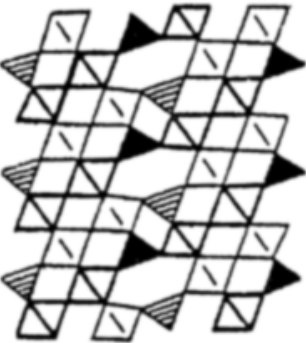

b

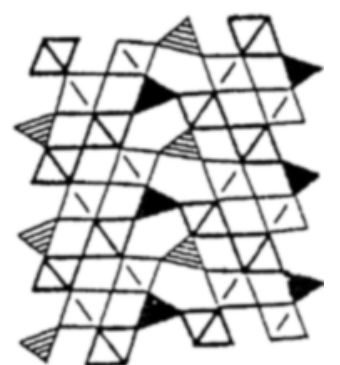

c

Figure 12. Lateral connection of the $\mathrm{ReO}_{3}$-type slabs bordered with (a) single $\mathrm{PO}$ tetrahedra, leading to (b) the monophosphate tungsten bronzes with hexagonal tunnels $\left(\mathrm{MPTB}_{\mathrm{H}}\right)$ and to (c) the monophosphate bronzes with pentagonal tunnels (MPTB $)$. 

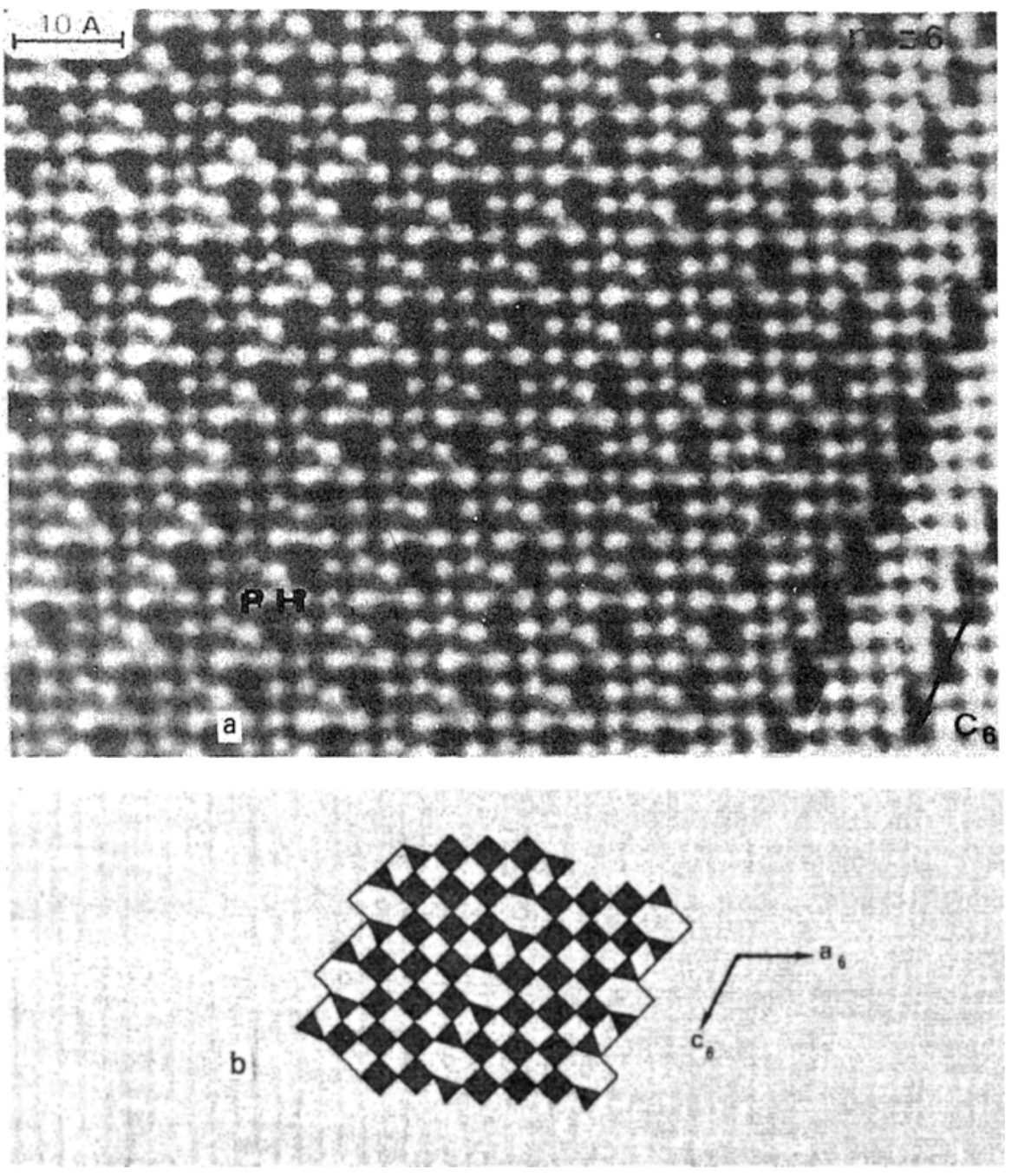

Figure 13. (a) An HREM image of $\mathrm{Ba}\left(\mathrm{P}_{2} \mathrm{O}_{4}\right)_{2}\left(\mathrm{WO}_{3}\right)_{12}(m=6)$ projected down the $\mid 010$ direction at about $-600 \AA$ underfocus. The white spots correspond to perovskite (P) and hexagonal (H) tunnels respectively. (b) Idealized structure of $m=6$.

$\mathrm{BaMo}_{2} \mathrm{P}_{2} \mathrm{O}_{12}$ is very similar to that of $\mathrm{NaPWO}_{6}$. the mixed chains of octahedra and tetrahedra form the same helicodal arrangement. The main differences concern the tilting and the distortion of the polyhedra.

The recent study of the ternary oxides of molybdenum and phosphorus shows that molybdenum can also participate in the formation of tunnel structures involving $\mathrm{PO}_{4}$ tetrahedra. $\mathrm{K}_{4} \mathrm{Mo}_{8} \mathrm{P}_{12} \mathrm{O}_{52}$ and $A \mathrm{Mo}_{2} \mathrm{P}_{3} \mathrm{O}_{12}(A=\mathrm{K}, \mathrm{Tl}, \mathrm{Rb})$ characterized by the pentavalent and tetravalent states of molybdenum are two examples of such structures. The host lattice of the oxide $\mathrm{K}_{4} \mathrm{Mo}_{8} \mathrm{P}_{12} \mathrm{O}_{52}$ is very complex (figure 24); it is built up from corner-sharing $\mathrm{MoO}_{6}$ octahedra, $\mathrm{PO}_{4}$ tetrahedra and diphosphate groups $\mathrm{P}_{2} \mathrm{O}_{7}$. 

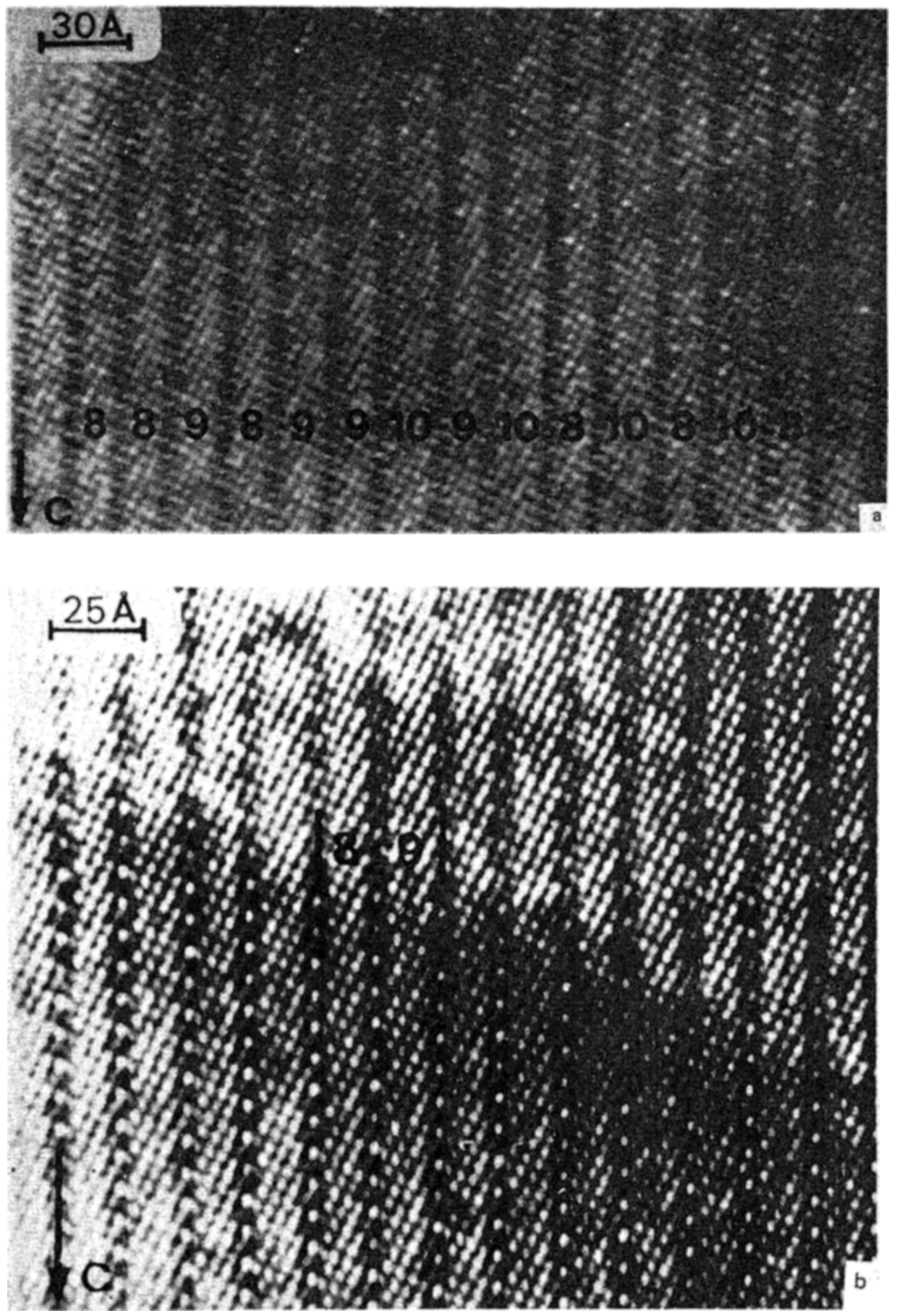

Figure 14. HREM images of intergrowths in the DPTB $\mathrm{Ha}\left(\mathrm{P}_{2} \mathrm{O}_{4}\right)_{4}\left(\mathrm{WO}_{3}\right)_{2 m}$ : (a) disordered crystal corresponding to the intergrowth of $m=8,9$ and 10 members, (b) ordered intergrowth of the members $m=8$ and 9 . 


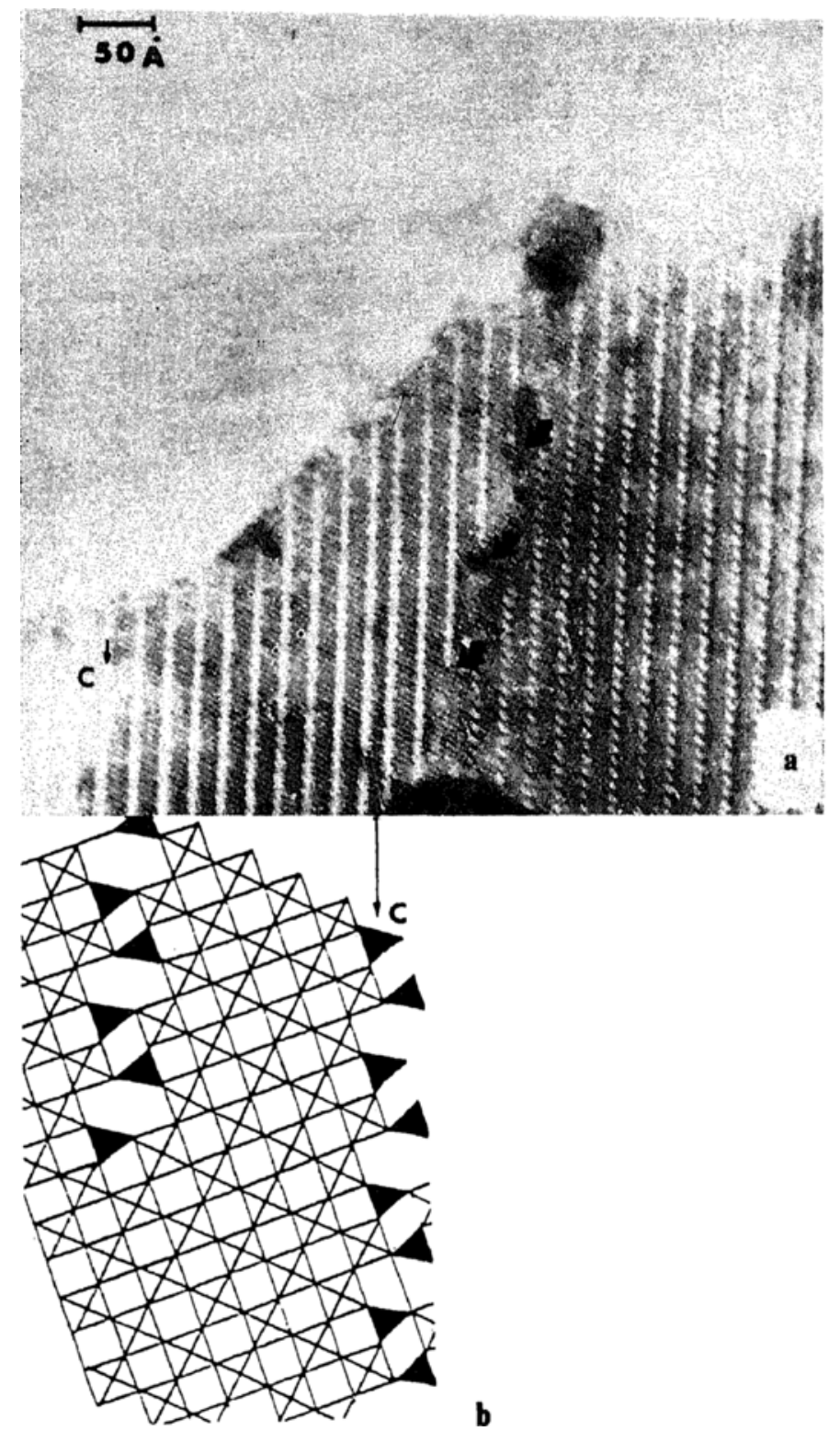

Figure 15. (a) Termination of the 'diphosphate rows' in an $m=11$ member of the potassium $\mathrm{DPTB}_{\mathrm{H}}$, and (b) idealized drawing of such a phenomenon.

Every $\mathrm{MoO}_{6}$ octahedron shares five corners with the $\mathrm{PO}_{4}$ and $\mathrm{P}_{2} \mathrm{O}_{7}$ groups, the sixth corner being free. It is worth noting that each $\mathrm{P}_{2} \mathrm{O}_{7}$ group shares two oxygen atoms with the same octahedron. In this framework the $\mathrm{P}_{2} \mathrm{O}_{7}$ and $\mathrm{PO}_{4}$ groups form different layers. Although the ' $\mathrm{O}_{6}$ ' octahedron surrounding the molybdenum ion is almost regular, the metal ion is strongly off-centre so that its coordination is better described as 

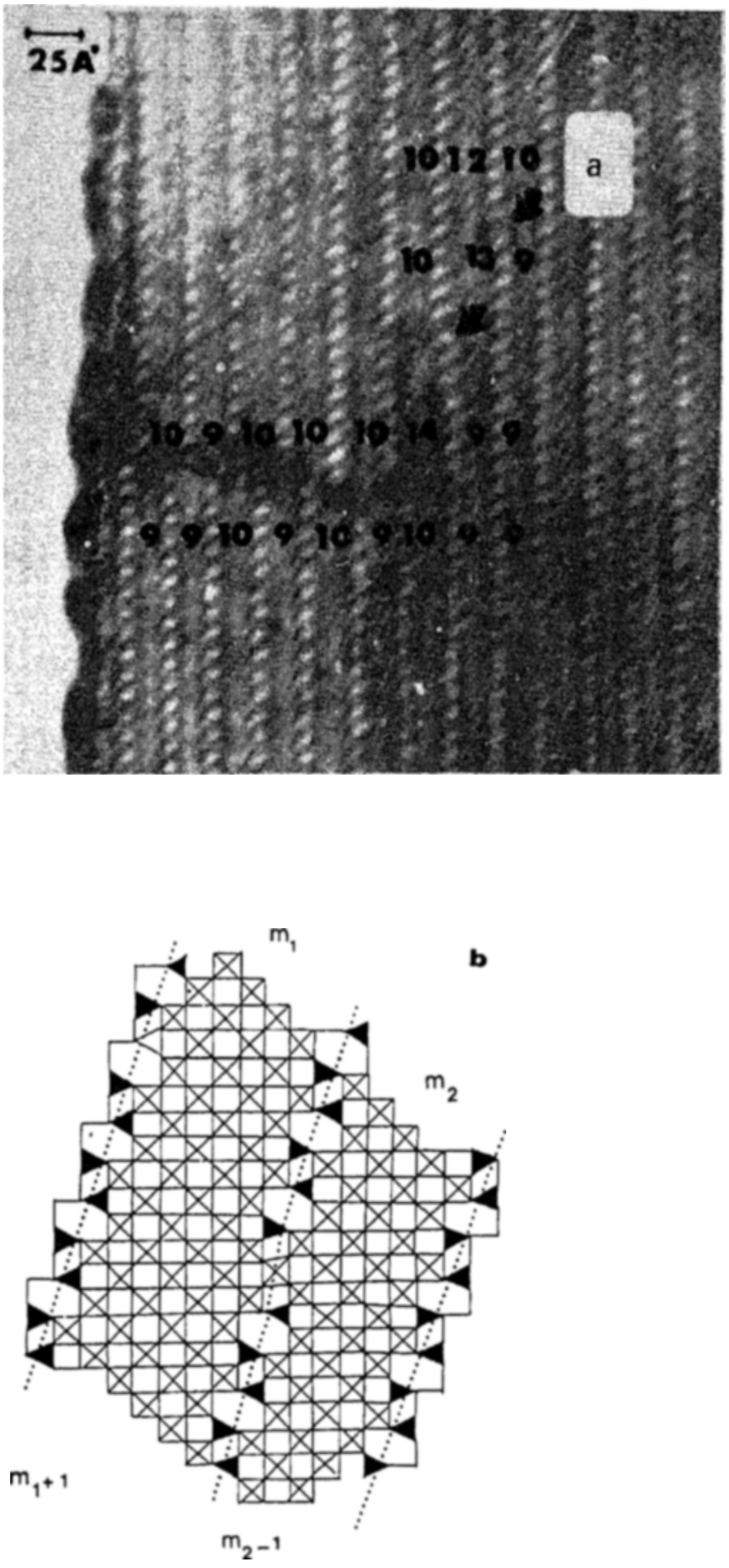

Figure 16. (n) Series of adjacent defects in a potassium DPTB $\mathrm{B}_{\mathrm{H}}$ crystal, $m=12$. An additional ' $\mathrm{P}_{2} \mathrm{O}_{7}$ row' appears. The adjacent rows swing (labelled $\mathrm{C}$ ) in the neighbouring of the defect. (b) Idealized drawing of the shift of a tunnel-row. 

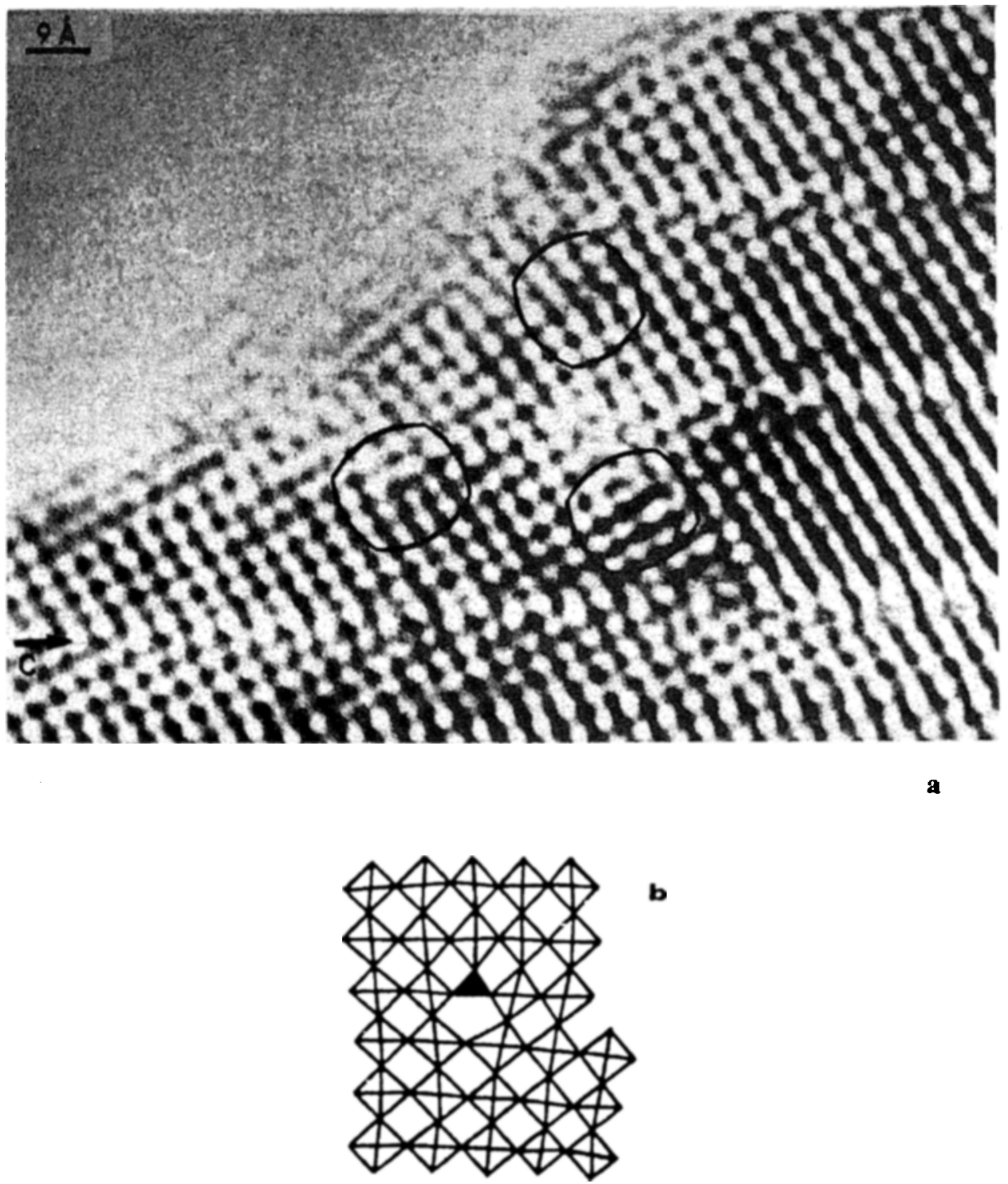

Figure 17. HREM micrograph showing (a) the formation of a dislocation in a $\mathrm{ReO}_{3}$ matrix, due to (b) the presence of a diphosphate group.

a $\mathrm{MoO}_{s}$ pyramid. The size of the tunnels where the $\mathrm{K}^{+}$ions are located is close to those observed in octahedral structures.

The molybdenophosphate $A \mathrm{Mo}_{2} \mathrm{P}_{3} \mathrm{O}_{12}$ has its host lattice built up from cornersharing $\mathrm{PO}_{4}$ tetrahedra, diphosphate groups $\mathrm{P}_{2} \mathrm{O}_{7}$ and $\mathrm{MoO}_{6}$ octahedra forming hexagonal tunnels where the $A$ ions are located (figure 25). This structure is characterized by chains of polyhedra in which units of two corner-sharing octahedra alternate with $\mathrm{P}_{2} \mathrm{O}_{7}$ groups as in the bronze $\mathrm{CsP}_{8} \mathrm{~W}_{8} \mathrm{O}_{40}$. The similarity of this 


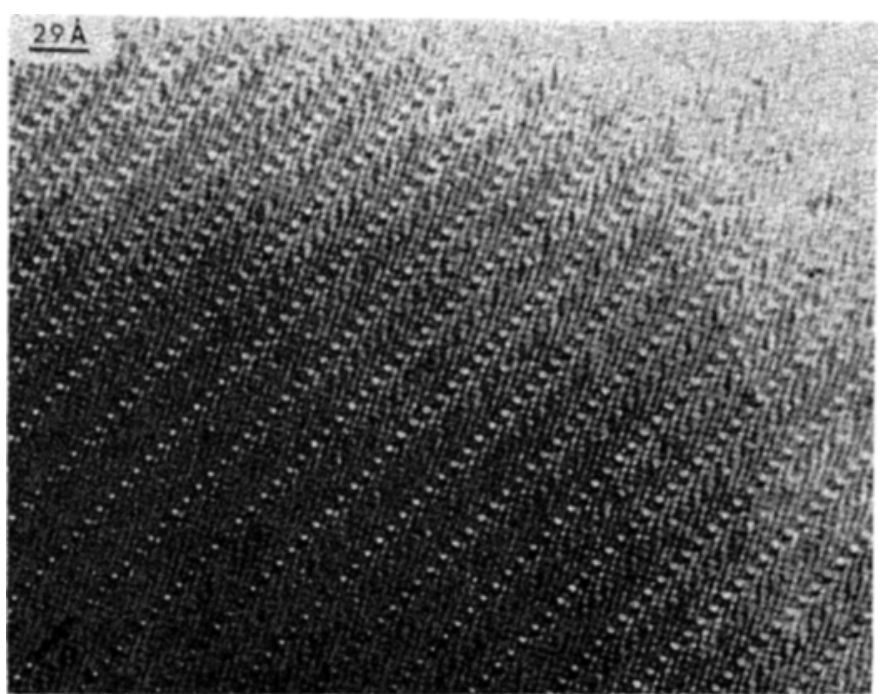

a

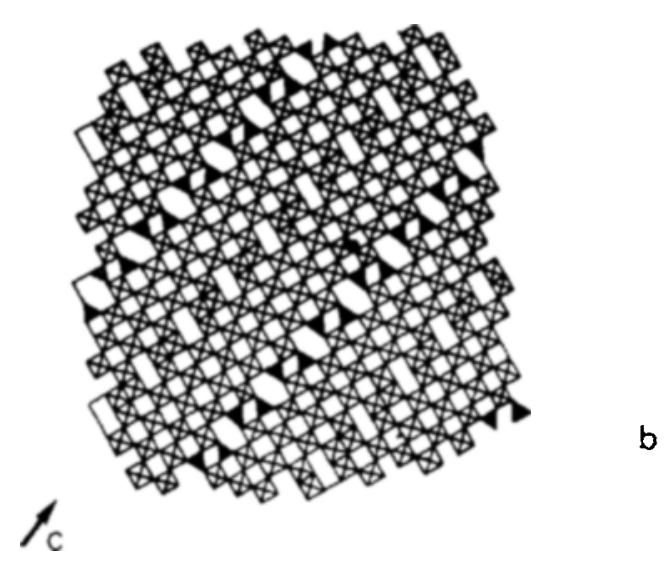

Figure 18. (a) Micrograph of a thin crystal of DPTB $\mathrm{K}\left(\mathrm{P}_{2} \mathrm{O}_{4}\right)_{2}\left(\mathrm{WO}_{3}\right)_{2 m}(m=19)$ showing a quasi regular sequence of $\{102\} \mathrm{CS}$ planes and (b) idealized drawing of the corresponding structure.

structure with the bronze $\mathrm{CsP}_{8} \mathrm{~W}_{8} \mathrm{O}_{40}$ is shown in figure 26 . In both structures one observes similar double chains (figure 26b) in which every $\mathrm{P}_{2} \mathrm{O}_{7}$ group shares two corners with a $\mathrm{Mo}_{2} \mathrm{O}_{11}$ unit formed of two octahedra. However, the relative orientation of two successive chains is different in both structures. Moreover the $\mathrm{P}_{8} \mathrm{~W}_{8} \mathrm{O}_{40}$ framework (figure 26c) is only built up from these double chains, whereas in the $\mathrm{Mo}_{2} \mathrm{P}_{3} \mathrm{O}_{12}$ host lattice these double chains are linked through simple $\mathrm{PO}_{4}$ tetrahedra (figure 26b). The structure of $T 1 \mathrm{Mo}_{2} \mathrm{P}_{3} \mathrm{O}_{12}$ is also closely related to that of the hexagonal tungsten bronze of Magneli. 


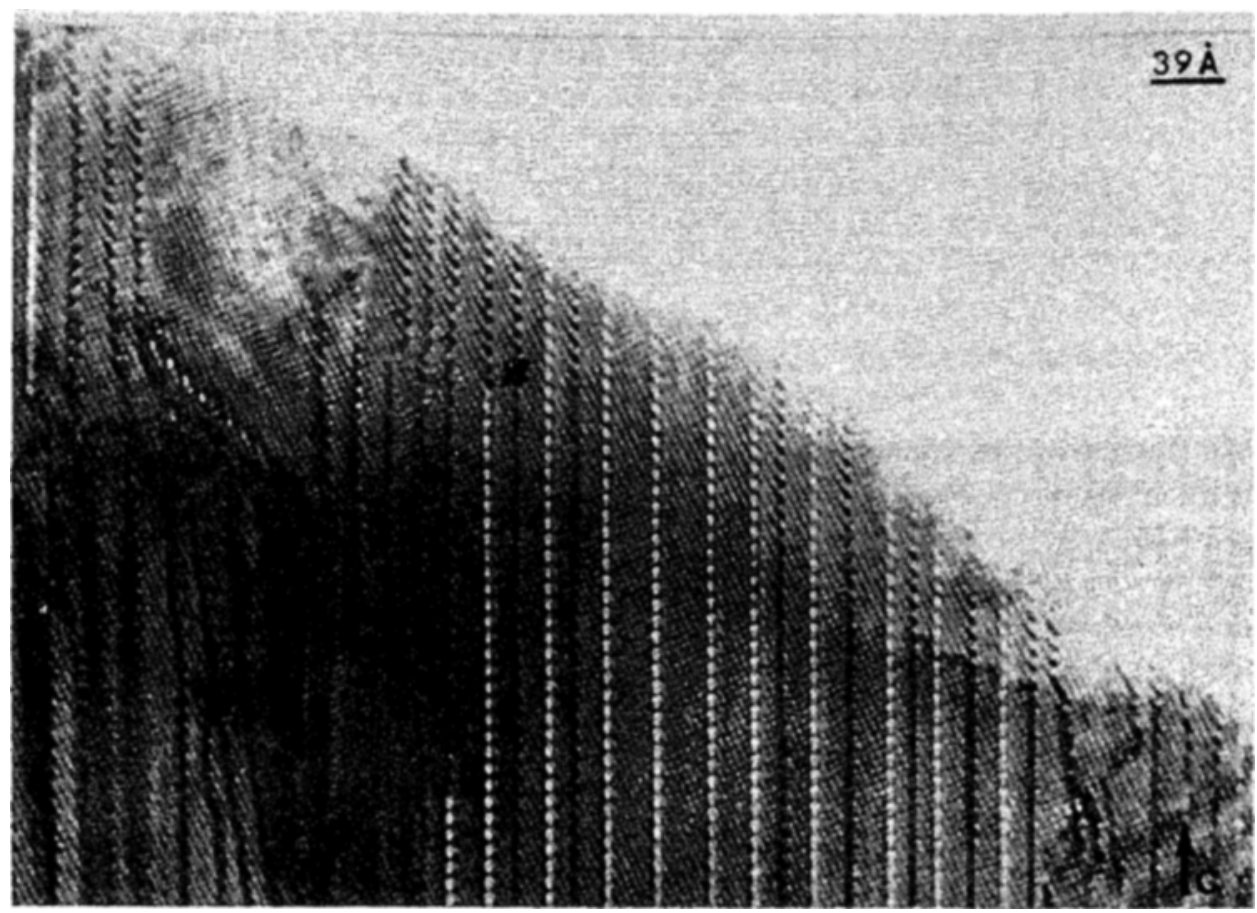

Figure 19. Complex association of diphosphate planes and crystallographic shear planes showing: lateral intergrowths of $\{102\}$ CS planes and diphosphate planes, longitudinal intergrowths of $\{102\}$ CS planes and diphosphate planes, formation of $\{103\}$ CS planes in the $\mathrm{ReO}_{3}$-type matrix.

Consideration of this host lattice along another direction shows that it can be described as a stacking of identical layers (figure 27) of polyhedra which are characterized by hexagonal rings deduced from those of $\mathrm{HT}$ B by replacing two octahedra by two $\mathrm{PO}_{4}$ tetrahedra.

The oxide $\mathrm{V}_{2} \mathrm{P}_{2} \mathrm{O}_{9}$ represents the limit case of the tunnel structures characterized by a mixed framework. In such a lattice (figure 28) chains of $\mathrm{ReO}_{3}$-type are associated by the edges of their octahedra forming pairs. These double files are connected through $\mathrm{P}_{2} \mathrm{O}_{7}$ groups as in the diphosphate bronzes. Consequently this framework delimits square tunnels and diamond-shaped tunnels as in phosphate tungsten bronzes. It must also be pointed out that the vanadium ion is off centered in its octahedron so that it is more exactly characterized by a pyramidal coordination.

4. Mixed frameworks involving silicophosphate groups (Hagman and Kierkegaard 1968; Goodenough et al 1976; Leclaire et al 1984, 1985a, 1986)

The possibility of associating $\mathrm{SiO}_{4}$ and $\mathrm{PO}_{4}$ tetrahedra to $\mathrm{MO}_{6}$ octahedra in order to build a three-dimensional framework characterized by tunnels is not obvious if one 


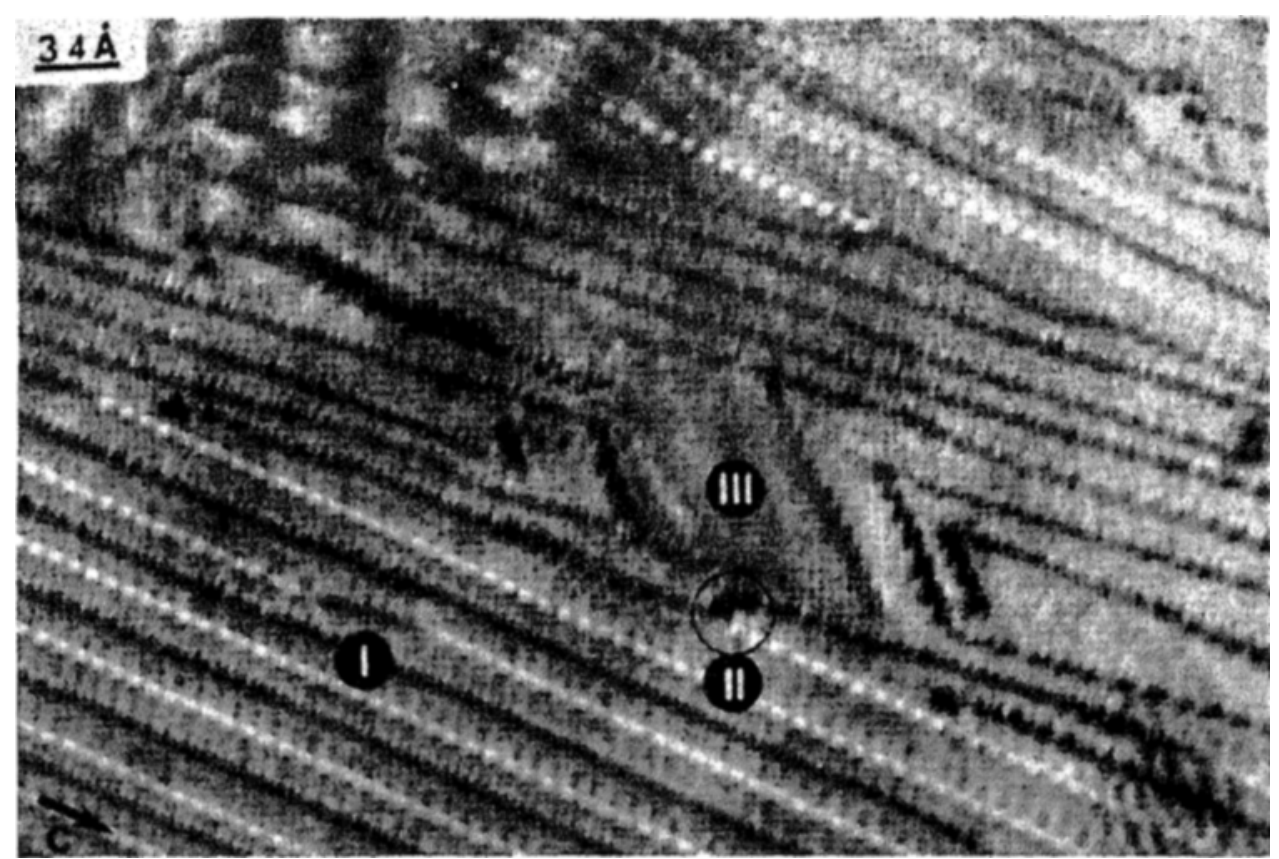

Figure 20. Complex association of diphosphate planes and crystallographic shear planes: detail of an HREM micrograph taken from a crystal $\mathrm{K}\left(\mathrm{P}_{2} \mathrm{O}_{4}\right)_{2}\left(\mathrm{WO}_{3}\right)_{2 m}$ with $m=38$. Zones I and II illustrate different types of interactions between diphosphate planes and shear planes. Zone III shows a hair-pin like contrast.

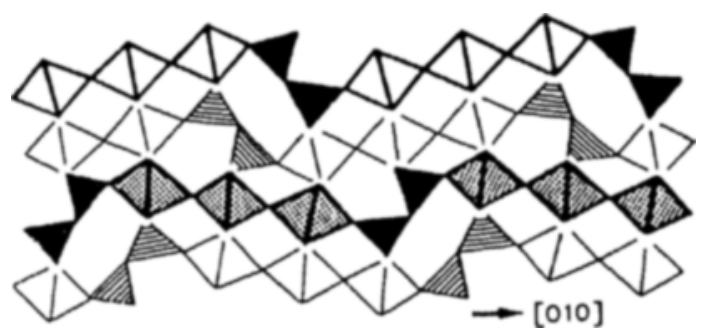

Figure 21. Structure of the oxide $\mathrm{P}_{8} \mathrm{~W}_{12} \mathrm{O}_{52}$.

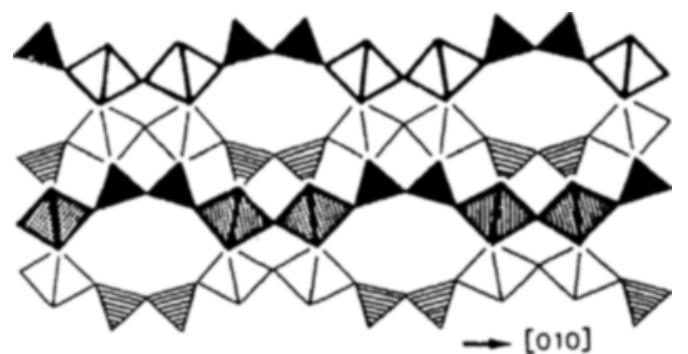

Figure 22. Structure of the bronze $\mathrm{Cs}_{8} \mathrm{~W}_{8} \mathrm{O}_{40}$. 

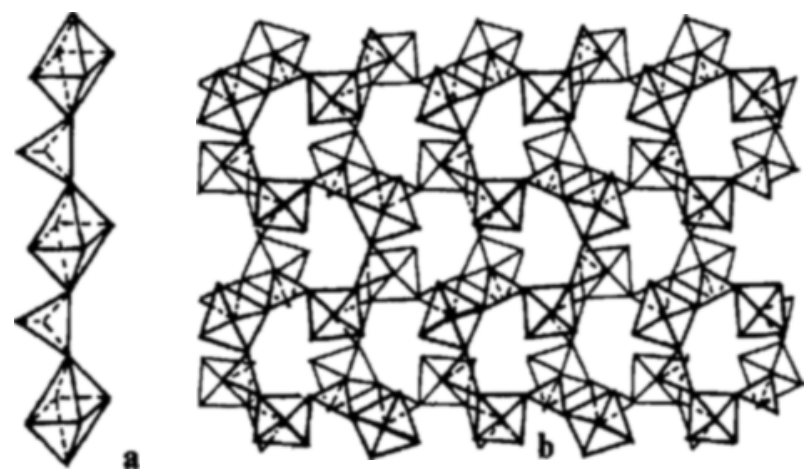

Figure 23. $\mathrm{NaPWO}_{6}$. (a) The infinite chains built up from $\mathrm{WO}_{6}$ octahedra and $\mathrm{PO}_{4}$ tetrahedra. (b) Lateral connection between the mixed chains forming an octahedral arrangement.

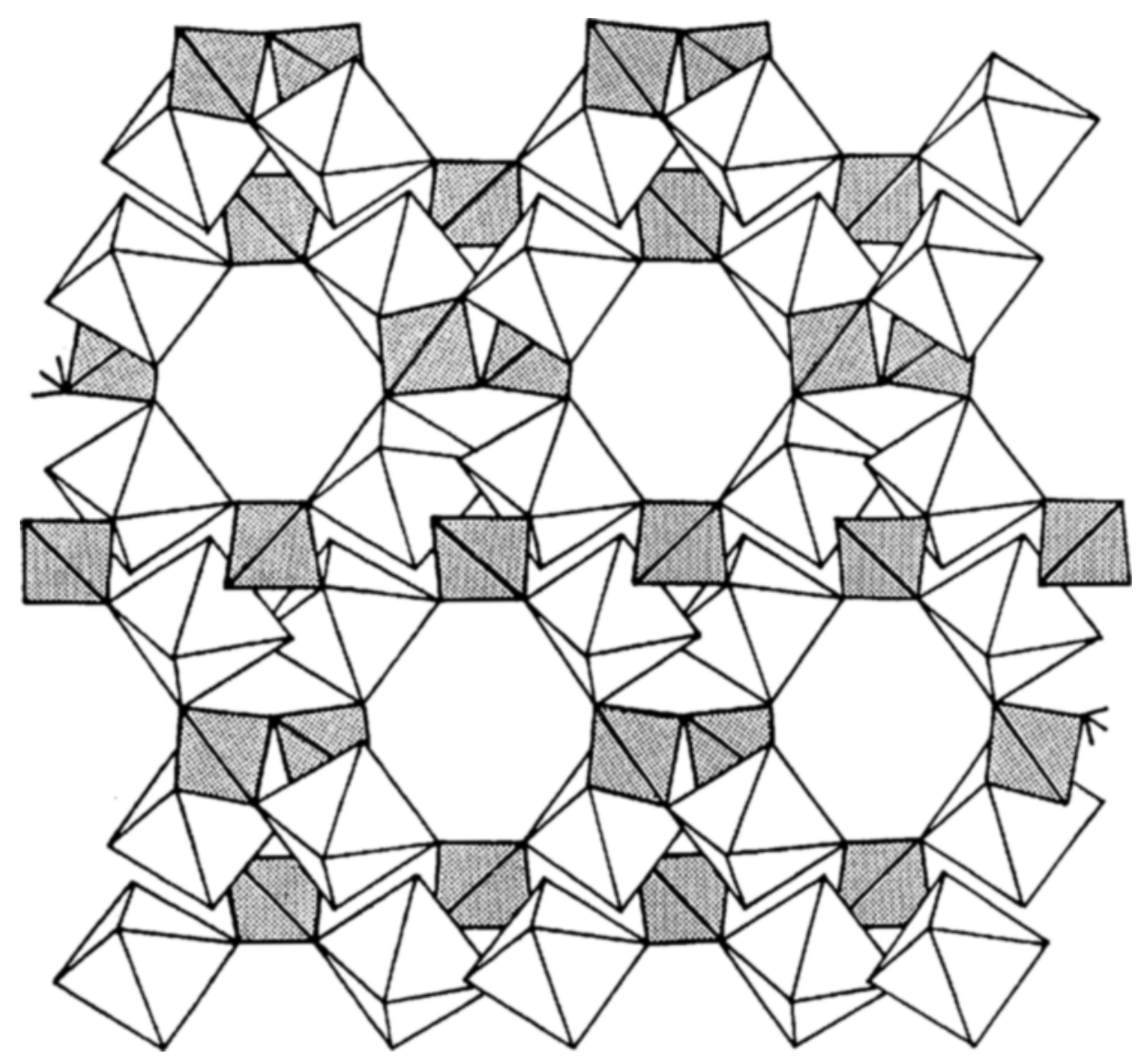

Figare 24. The host lattice of the molybdenophosphate $\mathrm{K}_{4} \mathrm{MO}_{8} \mathrm{P}_{12} \mathrm{O}_{32}$. 


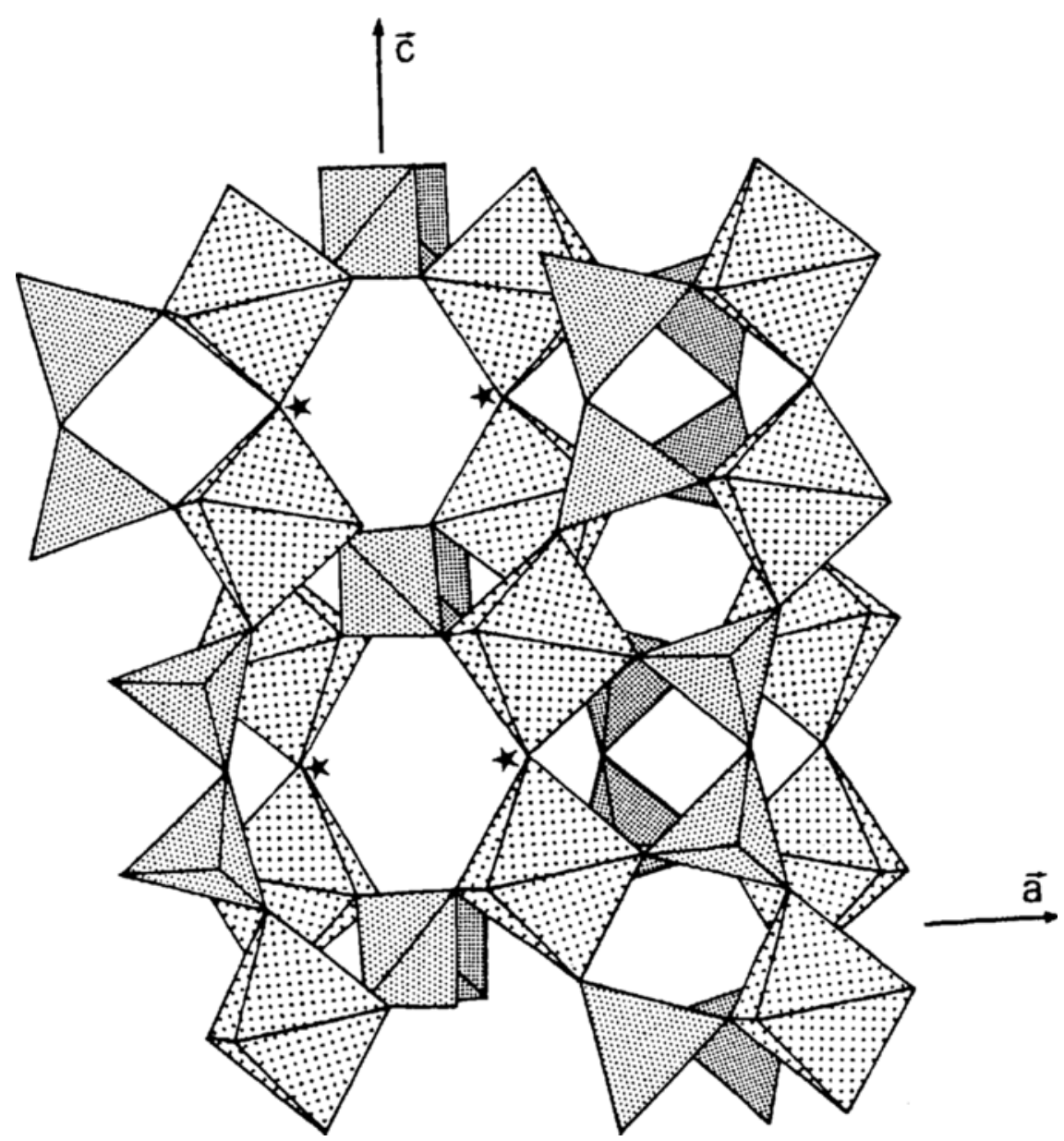

Figure 25. The host lattice of the molybdenum phosphate $\mathrm{TlMo}_{2} \mathrm{P}_{3} \mathrm{O}_{12}$.

takes into account the great rigidity of the $\mathrm{SiO}_{4}$ and $\mathrm{PO}_{4}$ tetrahedra. Three examples of such frameworks are given by the silicophosphates $A M_{3} \mathrm{P}_{6} \mathrm{Si}_{2} \mathrm{O}_{25}, \mathrm{~V}_{3} \mathrm{P}_{5} \mathrm{SiO}_{19}$ and $\mathrm{Na}_{1+x} \mathrm{Zr}_{2} \mathrm{P}_{3-x} \mathrm{Si}_{x} \mathrm{O}_{12}$.

The hexagonal silicophosphates $A M_{3} \mathrm{P}_{6} \mathrm{Si}_{2} \mathrm{O}_{25}(A=\mathrm{K}, \mathrm{Rb}, \mathrm{Tl}, \mathrm{Cs} ; M=\mathrm{Mo}, \mathrm{Ti}, \mathrm{Sn})$ form a large family which is in fact represented by the oxide $\mathrm{KMO}_{3} \mathrm{P}_{5.8} \mathrm{Si}_{2} \mathrm{O}_{25}$. The corner-sharing polyhedra which form the host-lattice of these oxides (figure 29) is characterized by tetrahedral units $\mathrm{P}_{6} \mathrm{Si}_{2} \mathrm{O}_{25}$ which share their corners with $\mathrm{MoO}_{6}$ octahedra. The tetrahedral units are built up of disilicate groups which share their corners with $2 \times 3 \mathrm{PO}_{4}$ tetrahedra. This three-dimensional network delimits tunnels running along the $[100]$ and [110] directions. Consequently, these oxides are characterized by an intersecting tunnel structure and can exhibit ion exchange properties.

The hexagonal vanadosilicophosphate $\mathrm{V}_{3} \mathrm{P}_{3} \mathrm{SiO}_{19}$ can be considered as a limiting case owing to the very small size of its tunnels as shown from the projection of its 


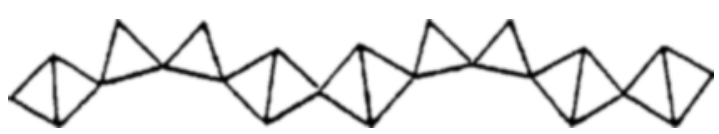

a

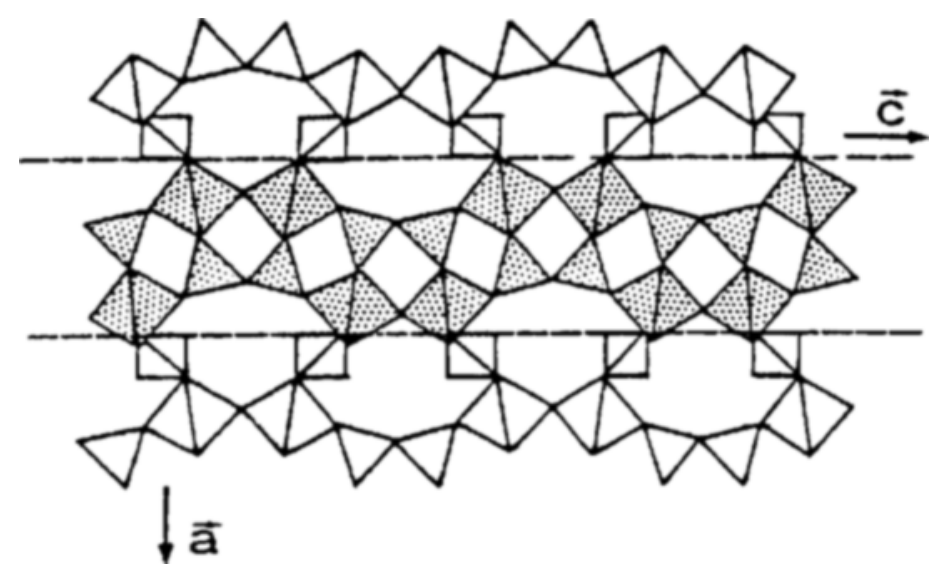

b

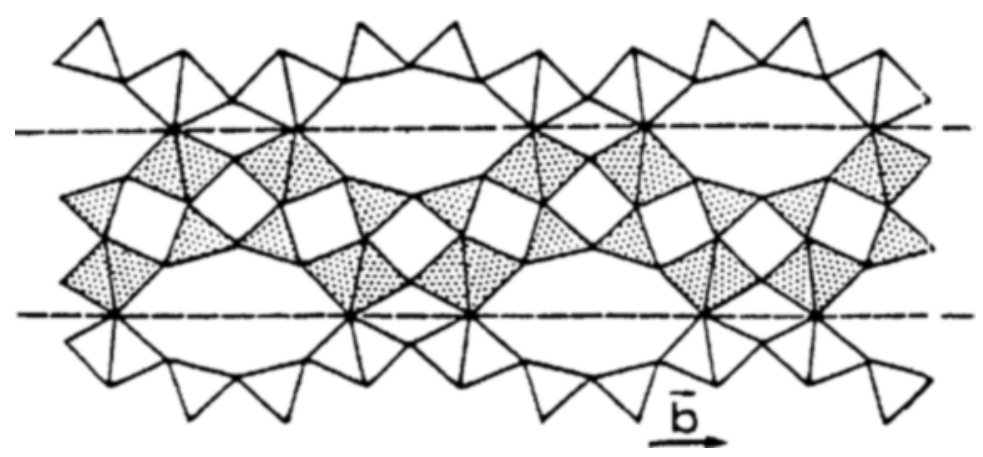

C

Figure 26. Comparison of the structure of the molybdenophosphate $\mathrm{TlMo}_{2} \mathrm{P}_{3} \mathrm{O}_{12}$ with that of the bronze $\mathrm{Cs}_{8} \mathrm{~W}_{8} \mathrm{O}_{40}$. (a) The infinite chains built up from diphosphate groups and $\mathrm{Mo}_{2} \mathrm{O}_{11}$ octahedral units. Relative dispositions and modes of connection of these chains (b) in the oxide $\mathrm{TIMO}_{2} \mathrm{P}_{3} \mathrm{O}_{12}$ and (c) and in the bronze $\mathrm{CsP}_{8} \mathrm{~W}_{8} \mathrm{O}_{40}$.

structure on to the (001) plane (figure 30a). This oxide exhibits a great similarity with the true tunnel structure $\mathrm{KM}_{3} \mathrm{P}_{6} \mathrm{Si}_{2} \mathrm{O}_{25}$ (figure $30 \mathrm{~b}$ ): its framework is also built up from tetrahedral units $\mathrm{P}_{6} \mathrm{Si}_{2} \mathrm{O}_{25}$ sharing their corners with $\mathrm{VO}_{6}$ octahedra, but it differs from the silicomolybdate by the existence of $\mathrm{P}_{4} \mathrm{O}_{13}$ units built up from four 


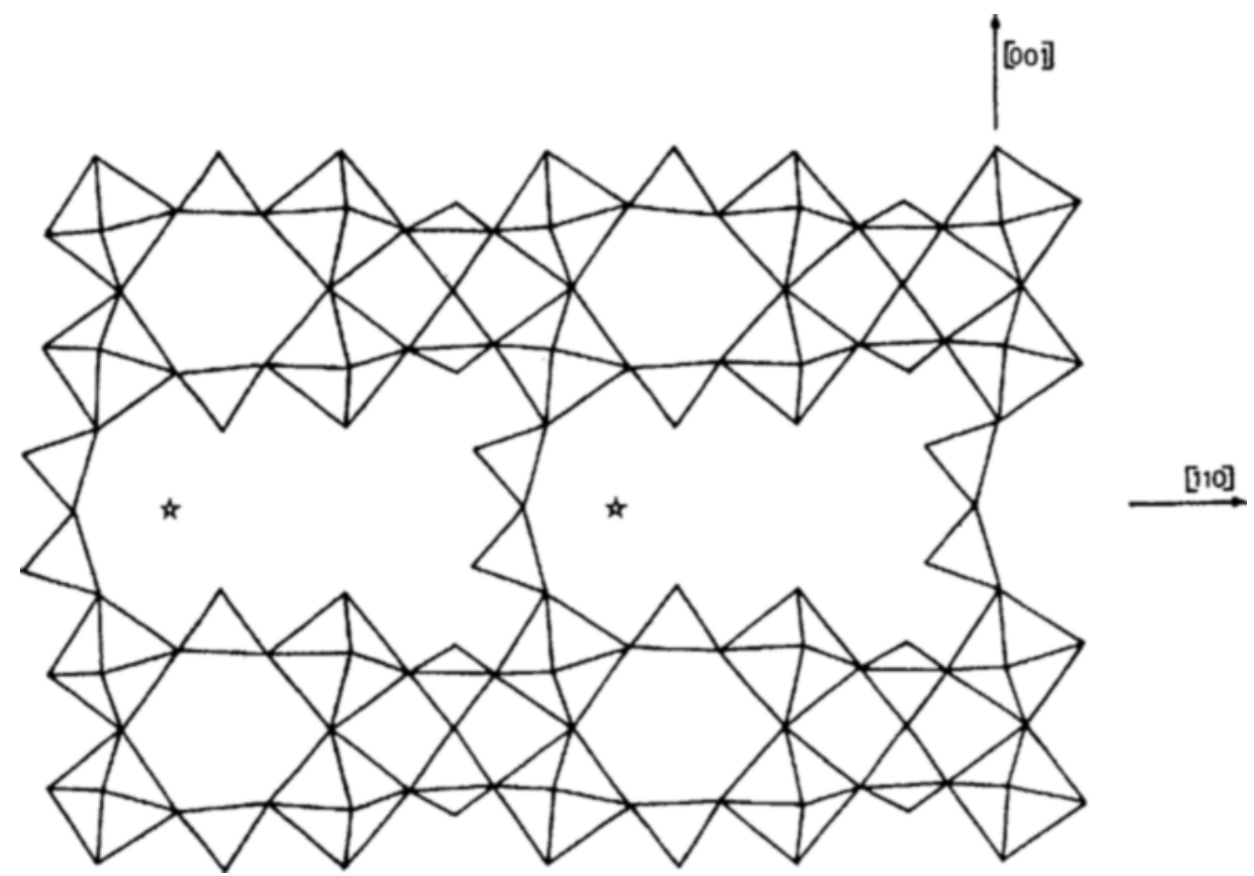

Figure 27. Similarity of $\mathrm{TIMO}_{2} \mathrm{P}_{3} \mathrm{O}_{12}$ with the HTB structure: the framework is built up from the stacking of identical layers of the polyhedra forming hexagonal rings.

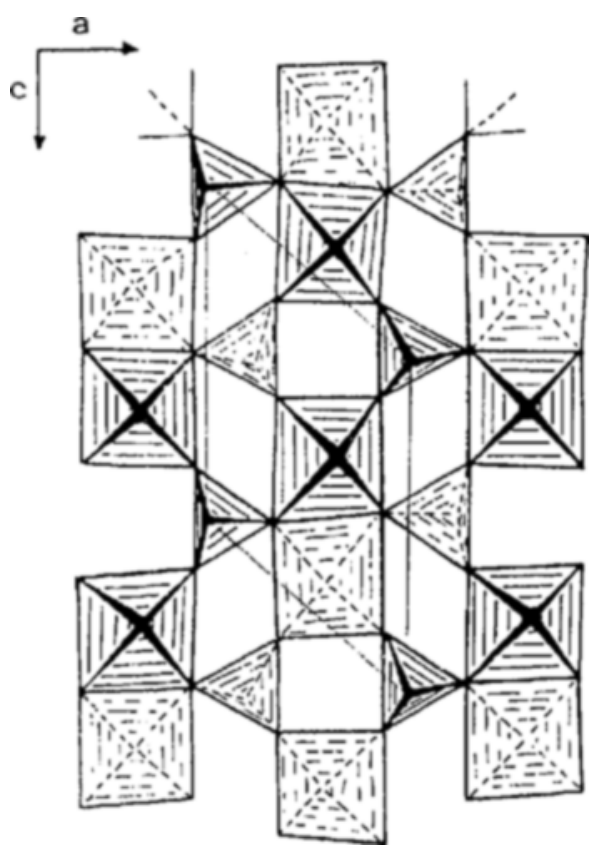

Figure 28. Structure of the vanadophosphate $\mathrm{V}_{2} \mathrm{P}_{2} \mathrm{O}_{9}$. 


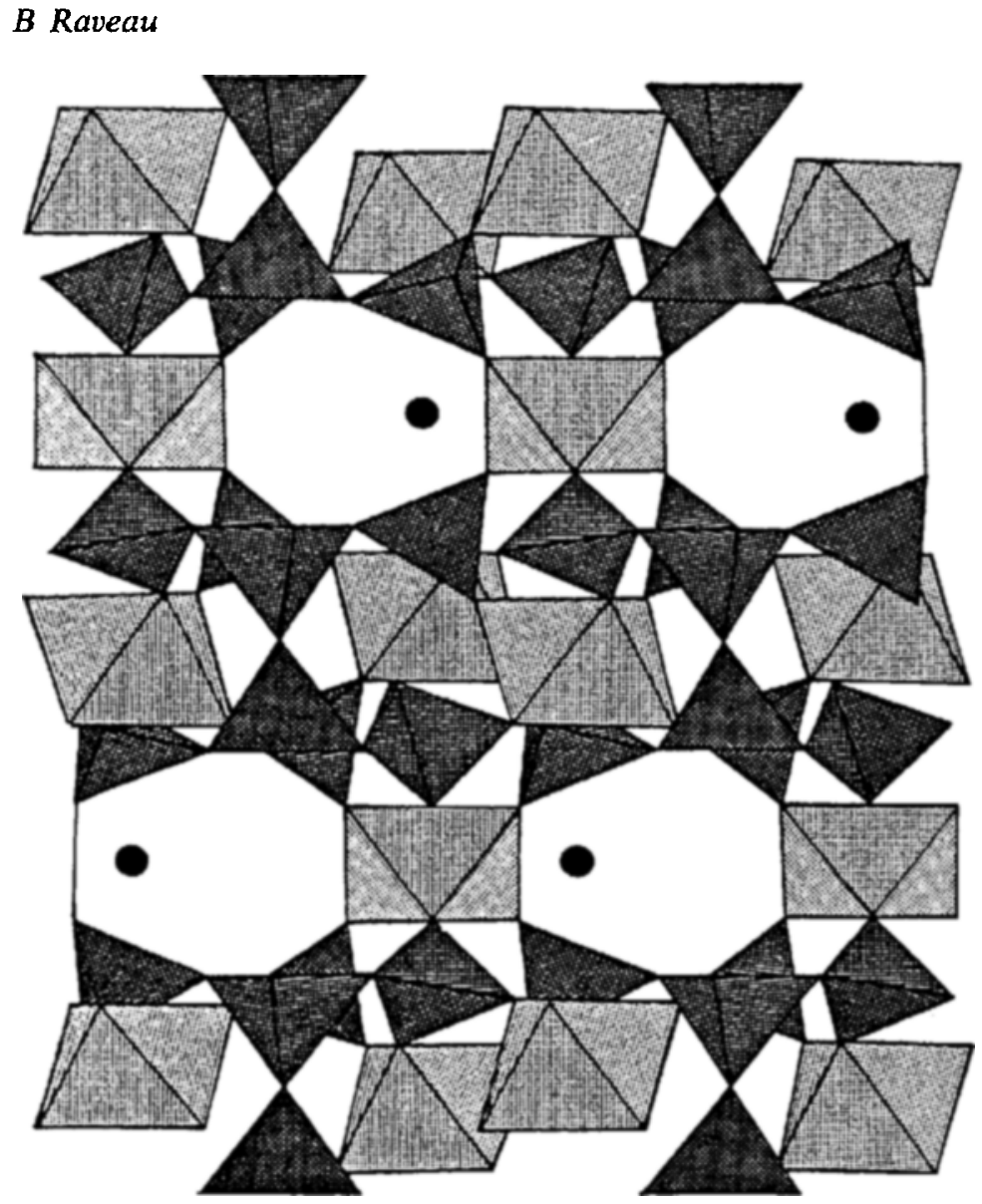

Figure 29. The host lattice of the hexagonal silicophosphate $\mathrm{KM}_{3} \mathrm{P}_{6} \mathrm{Si}_{2} \mathrm{O}_{25}$.

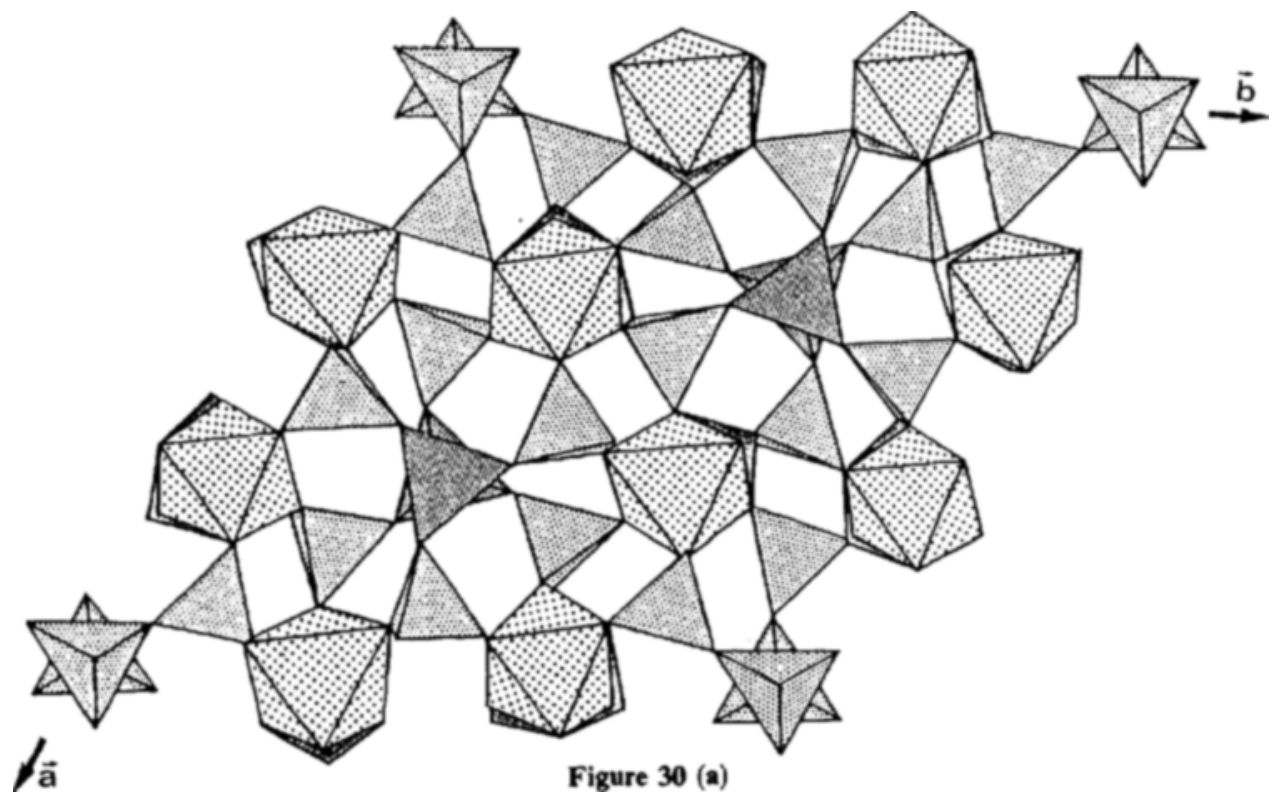



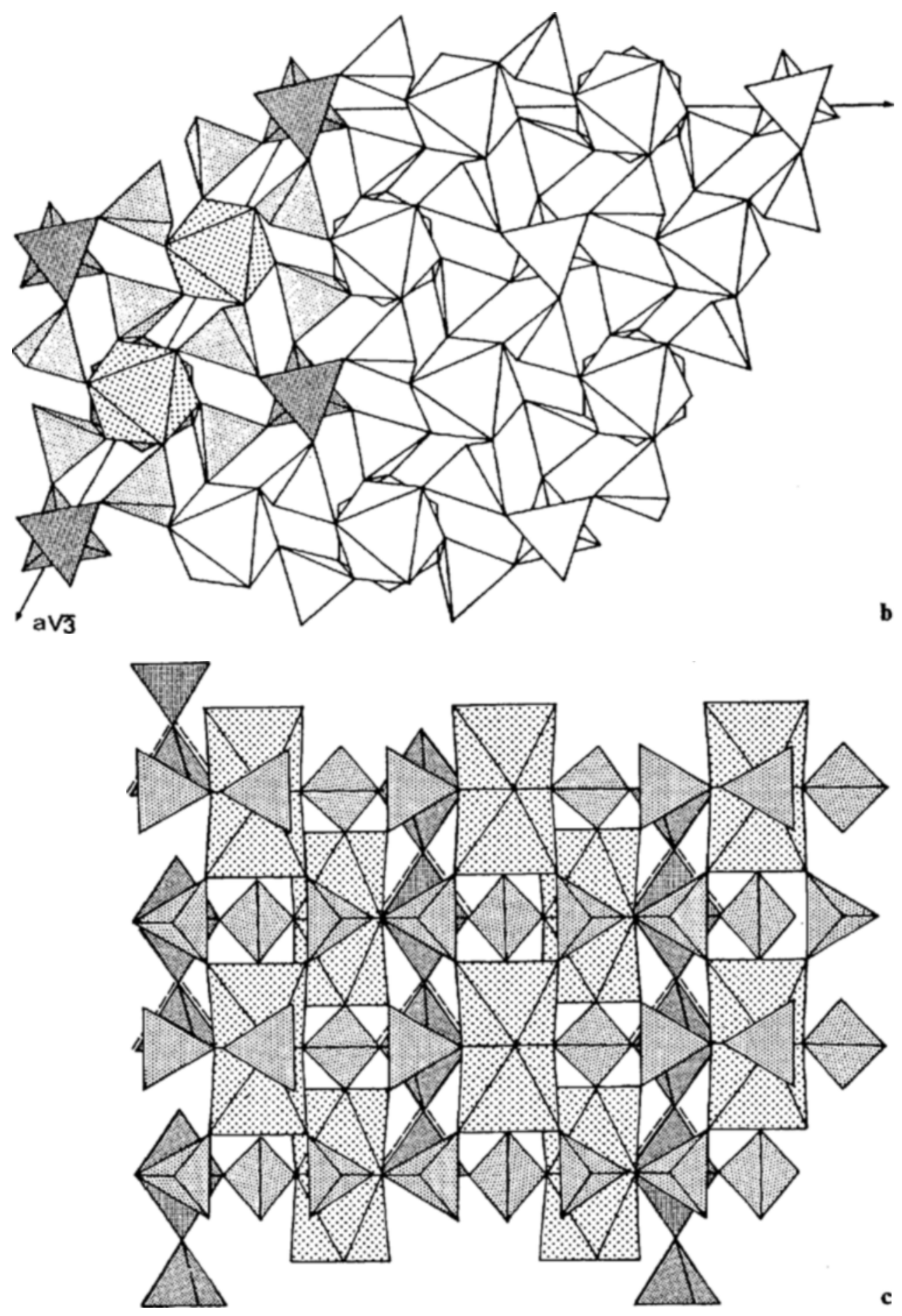

Figure 30. Projection of (a) the structure of the vanadosilicophosphate $\mathrm{V}_{3} \mathrm{P}_{5} \mathrm{SiO}_{1}$ on to the (001) plane compared to (b) the one of $\mathrm{KM}_{3} \mathrm{P}_{6} \mathrm{Si}_{2} \mathrm{O}_{2}$. (c) Three-dimensional view of the host-lattice of $\mathrm{V}_{3} \mathrm{P}_{5} \mathrm{SiO}_{19}$. 
corner-sharing tetrahedra. The three-dimensional view of this structure (figure 30c) shows another particularity of this structure: the presence of octahedral clusters composed of two face-sharing octahedra; these clusters form infinite chains with the $\mathrm{PO}_{4}$ tetrahedra extending along $c$, which can be compared to the strings $\left[\mathrm{MoP}_{2} \mathrm{O}_{15}\right]_{3}$ built up of three octahedra and six tetrahedra observed in the oxide $A M_{3} \mathrm{P}_{6} \mathrm{Si}_{2} \mathrm{O}_{25}$.

The silicophosphates $\mathrm{Na}_{1+x} \mathrm{Zr}_{2} \mathrm{P}_{3-x} \mathrm{Si}_{x} \mathrm{O}_{12}$ could be classified as phosphates as well as silicates since their homogeneity range extends from $x=0$ to $x=3$. In these compounds each $\mathrm{ZrO}_{6}$ octahedron shares its six corners with $\mathrm{SiO}_{4}$ and/or $\mathrm{PO}_{4}$ tetrahedra, and each tetrahedron shares its four corners with four octahedra as shown in figure 31a. This mixed framework $\mathrm{Zr}_{2} \mathrm{P}_{3-x} \mathrm{Si}_{x} \mathrm{O}_{12}$ does not really form tunnels but large cavities (figure 31b) where the $\mathrm{Na}^{+}$ions are located; however these cavities communicate with one another so that $\mathrm{Na}^{+}$ions can move through the structure, involving superionic conductivity properties for these materials. It is worth noting that zirconium may be replaced by titanium or germanium.

5. Other examples of mixed frameworks of octahedra and tetrahedra (Lloyd et al 1976; Stone and Bursill 1977; Bursil 1979; Bursill and Stone 1981; Gasperin 1981; Agafonov 1985)

Besides the silicates, germanates and phosphates, few oxides with a mixed framework involving tetrahedra and octahedra are known, if one excepts the oxygen-deficient perovskites. The niobate, $\mathrm{Cs}_{2} \mathrm{Nb}_{4} \mathrm{O}_{11}$, is an interesting example owing to the great size

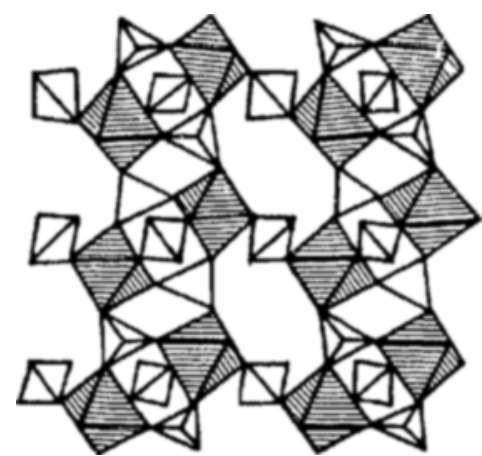

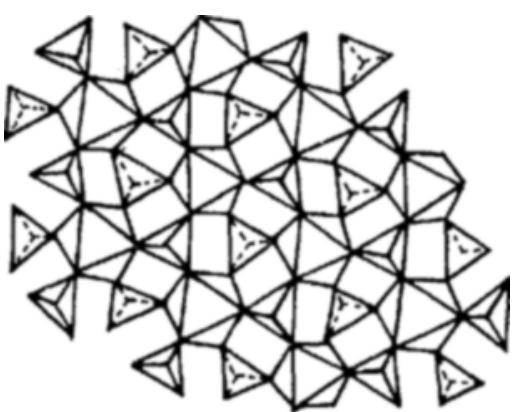

$\mathbf{b}$

Figure 31. $\mathrm{NaZr}_{2}\left(\mathrm{PO}_{4}\right)_{3}$. (a) Three-dimensional view of the structure along the $C_{R}$ direction of the rhombohedral cell. (b) Projection of half the unit cell along the $a_{R}$ axis.

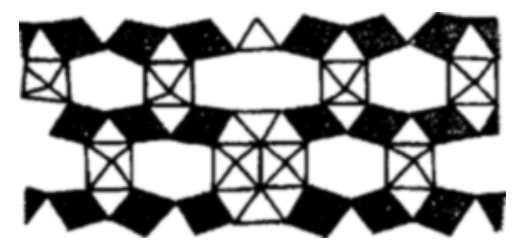

Figure 32. The host-lattice of the niobate $\mathrm{Cs}_{2} \mathrm{Nb}_{4} \mathrm{O}_{11}$. 
of its tunnels; the important family of oxides $\mathrm{Ga}_{4} \mathrm{O}_{6}\left(M \mathrm{O}_{2}\right)_{n}(M=\mathrm{Ti}, \mathrm{Ge})$ is worth describing owing to its analogy with the shear structures and the DPTB.

The host-lattice of the niobate $\mathrm{Cs}_{2} \mathrm{Nb}_{4} \mathrm{O}_{11}$ (figure 32) is mainly built up of corner and edge-sharing octahedra; however a small number of $\mathrm{NbO}_{4}$ tetrahedra participate in the structure. A striking similarity with the pyrochlore framework is observed as shown from the hexagonal tunnels running in different directions. The main difference with pyrochlores concerns the groups of two edge-sharing octahedra and their association with $\mathrm{NbO}_{4}$ tetrahedra leading to the formation of wide tunnels where the $\mathrm{Cs}^{+}$ions are located; these tunnels can be compared to those observed in $\mathrm{CsP}_{8} \mathrm{~W}_{8} \mathrm{O}_{40}$ and $A M_{3} \mathrm{P}_{6} \mathrm{Si}_{2} \mathrm{O}_{25}$. Like the pyrochlores this oxide is characterized by a true intersecting tunnel structure which should exhibit ion exchange properties.

The structure of $\beta-\mathrm{Ga}_{2} \mathrm{O}_{3}$ which exhibits an anionic close-packing can also be considered as the limiting case of a tunnel structure: its framework (figure 33a) which is built up from structural units of $\mathrm{Ga}_{4} \mathrm{O}_{24}$ formed of two $\mathrm{GaO}_{4}$ tetrahedra and two edgesharing $\mathrm{GaO}_{6}$ octahedra, delimits diamond shaped tunnels. These latter are very similar to those of the hypothetical structure $\mathrm{MO}_{2}$ (figure 33b) obtained by a simple tilting of the octahedra in the $\mathrm{MO}_{2}$ rutile form (figure 33c). The close relationships between the two structures, rutile and $\beta-\mathrm{Ga}_{2} \mathrm{O}_{3}$, are confirmed by the ability of the $\mathrm{Ga}_{4} \mathrm{O}_{24}$ units to fit the rutile framework. $\mathrm{Ga}_{4} \mathrm{O}_{24}$ units can be introduced into the $\mathrm{TiO}_{2}$ framework in the form of rows forming hexagonal tunnels which are empty. These rows delimit rutile slabs which are $n$ octahedra wide; thus a large family, $\mathrm{Ga}_{4} \mathrm{O}_{6}\left(\mathrm{MO}_{2}\right)_{n}$, can be predicted in which $n$ is an odd number which characterizes the number of octahedra corresponding to the width of the rutile slab; $\mathrm{Ga}_{4} \mathrm{GeO}_{3} \alpha, \mathrm{Ga}_{4} \mathrm{Ge}_{3} \mathrm{O}_{12}, \mathrm{Ga}_{4} \mathrm{Ti}_{5} \mathrm{O}_{16}$ correspond to the first, second and third members of this series whereas the oxide $\mathrm{Ga}_{4} \mathrm{Ti}_{21} \mathrm{O}_{48}$ represents the member $m=21$ (figure $34 a, b, c$ ). The similarity of this structural family with the shear structures and with the diphosphate tungsten bronzes must be pointed out: the ' $\left|\mathrm{Ga}_{4} \mathrm{O}_{6}\right|_{\infty}$ planes' correspond to the 'phosphate planes' or to the shear planes whereas the rutile slabs can be replaced by $\mathrm{ReO}_{3}$-type slabs in the DPTB. It is worth noting that the geometry of the ' $\mathrm{Ga}_{4} \mathrm{O}_{24}$ ' units does not allow the obtaining of an even number of octahedra for the rutile slabs; nevertheless the possibility of existence of even-n members resulting from the intergrowth of two odd- $m$ members can be considered as shown for the hypothetical member $m=4$ (figure 34d). The particular behaviour of the first member $\mathrm{Ga}_{4} \mathrm{GeO}_{8} \propto$ is also remarkable: the ' $\mathrm{Ga}_{4} \mathrm{O}_{24}$ ' units share their corners in

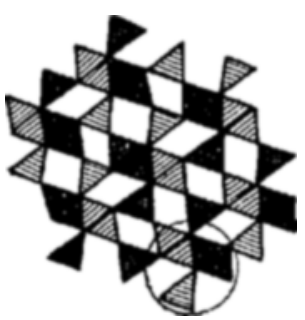

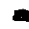

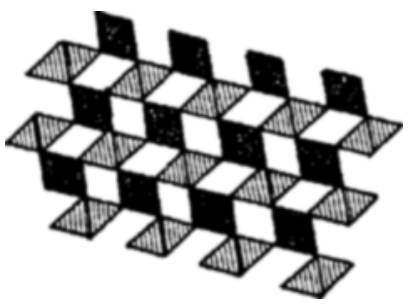

b

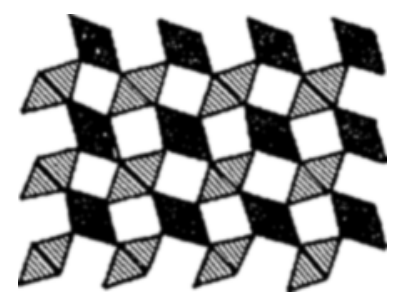

c

Figure 33. Comparison of (a) the $\beta-\mathrm{Ga}_{2} \mathrm{O}_{3}$, structure with (b) the hypothetical $\mathrm{MO}$ oxide derived from (c) the rutile $\mathrm{TiO}_{2}$ framework by tilting of the octahedra. One $\mathrm{Ga}_{4} \mathrm{O}_{34}$ unit is circled. 


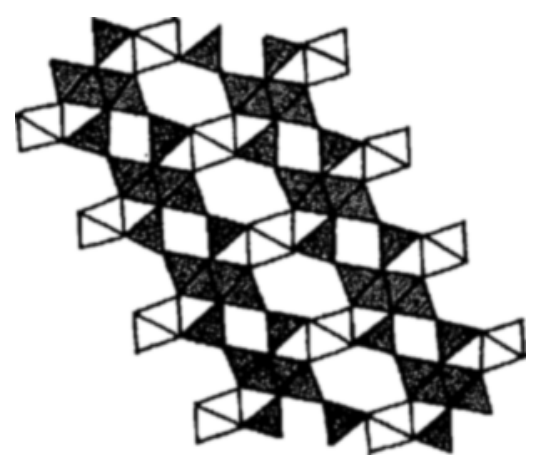

$\mathbf{a}$

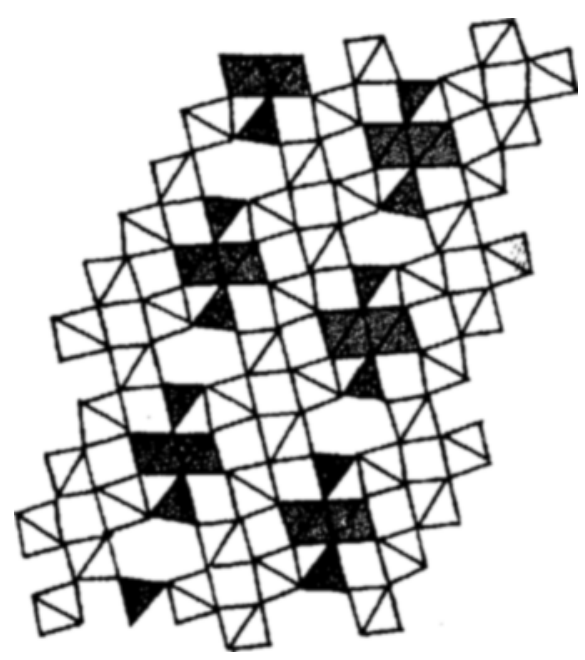

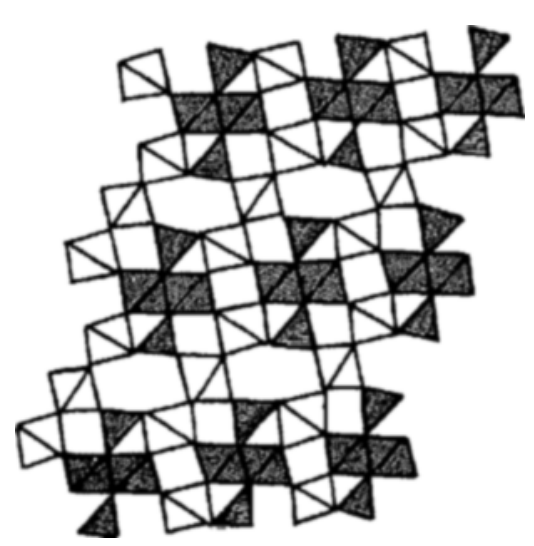

b

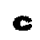

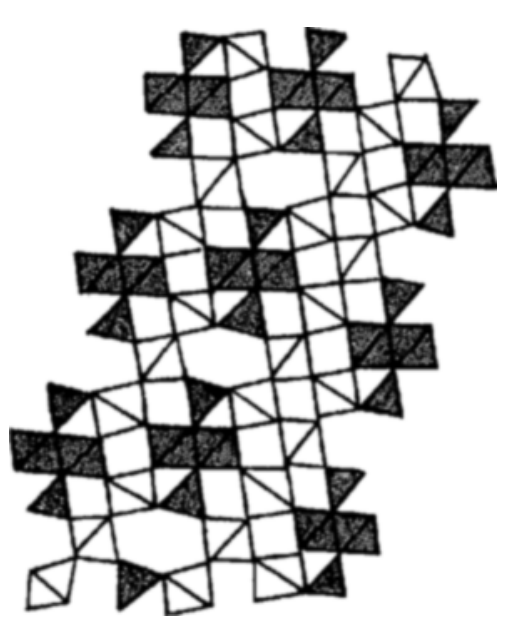

d

Figure 34. The three first odd members of the series $\mathrm{Ga}_{4} \mathrm{O}_{6}\left(M \mathrm{O}_{2}\right)_{n}(\mathrm{a}) n=1$, (b) $n=3$ and (c) $n=5$ and (d) the hypothetical even- $m$ member $m=4$ corresponding to the intergrowth of the members $n=3$ and $n=5$. The $\mathrm{Ga}_{4} \mathrm{O}_{6}$ units are hatched.

one direction forming ' $\beta$ - $\mathrm{Ga}_{2} \mathrm{O}_{3}$ '-type ribbons, so that an intergrowth between this oxide and $\beta-\mathrm{Ga}_{2} \mathrm{O}_{3}$ could be considered.

\section{Conclusion}

Oxides' with a three-dimensional mixed framework built up from octahedra and tetrahedra correspond to a rather recent field of investigation which seems rather promising. The adaptability of phosphate groups to an octahedral framework, especially to $\mathrm{WO}_{6}$ and $\mathrm{MoO}_{6}$ octahedra is remarkable, such structural properties 
should be used to induce a strong anisotropy in the metallic properties of those bronzes leading either to bidimensional conductors as in DPTB and MPTB or to unidimensional conductors as in $\mathrm{CsP}_{8} \mathrm{~W}_{8} \mathrm{O}_{40}$. The possibility of $\mathrm{SiO}_{4}$ and $\mathrm{GeO}_{4}$ tetrahedra forming a mixed framework seems more limited, owing to their great rigidity, nevertheless they show a good ability to connect with $\mathrm{NbO}_{6}$ or $\mathrm{TaO}_{6}$ octahedra. The investigation of mixed frameworks involving 'silicophosphates' groups is quite new, but the formation of an intersecting tunnel structure makes us think that it could be the starting point of the synthesis of tunnel structures intermediate between the octahedral frameworks and the tetrahedral zeolites. Gallium, is characterized by its tendency to form mixed frameworks owing to its ability to take up both octahedral and tetrahedral coordinations; moreover oxides such as $\mathrm{Ga}_{4} \mathrm{O}_{6}\left(\mathrm{TiO}_{2}\right)_{n}$ are potential candidates for intercalation of small ions like $\mathrm{Li}^{+}$or $\mathrm{Na}^{+}$.

\section{References}

Agafonov A 1985 Thèse de Doctorat de l'Universite de Paris VI Cristall-chimie des germates Al, Fe, Ge. Comparaisunarec celle des silicates

Benmoussa A, Groult D, Labbe Ph and Raveau B 1984 Acta Cryst. C40 573

Blasse G and Bril A $1970 \mathrm{~J}$. Solid State Chem. 2105

Bursill L A 1979 Acta Cryst. $\mathbf{B 3 5} 530$

Bursill L A and Stone G G 1981 J. Solid State Chem. 38149

Chailleux J M, Groult D and Raveau B 1978 Ann. Chim., Sci. Mater. 3251

Choisnet J, Deschanvres A and Raveau B 1972 J. Solid State Chem. 4209

Choisnet J, Deschanvres A and Tarte P 1976a Spectrochim. Acta A32 57

Choisnet J, Groult D, Raveau B and Gasperin M 1977a Acta Cryst. B33 1841

Choisnet J, Nguyen N, Groult D and Raveau B 1976b Mater. Res. Bull. 11887

Choisnet J, Nguyen N and Raveau B 1977b Mater. Res. Bull. 1291

Domenges B, Goreaud M, Labbe Ph and Raveau B 1982 Acta Cryst. B38 1724

Domenges B, Goreaud M, Labbe Ph and Raveau B 1983 J. Solid State Chem. 50173

Domenges B, Hervieu M and Raveau B 1984a Acta Cryst. B40 249

Domenges B, Hervieu M, Tilley R T D and Raveau B 1984 J. Solid State Chem. 5410

Domenges B, Hervieu M and Raveau B 1985 Chem. Script. 25361

Evans D M and Katz L 1973 J. Solid State Chem. 8150

Gasperin M 1981 Acta Cryst. B37 641

Giroult J P, Goreaud M, Labbe Ph and Raveau B 1981a Acta Cryst. B37 1163, 2139

Giroult J P, Goreaud M, Labbe Ph and Raveau B 1981b Acta Cryst. B38 2342

Giroult J P, Goreaud M, Labbe Ph and Raveau B 1982 J. Solid State Chem. 44407

Goodenough J B, Hong H Y P and Kafalas J A 1976 Mater. Res. Bull. 11203

Goreaud M, Deschanvres A and Raveau B 1973 Mater. Res. Bull. 81205

Goreaud M, Labbe Ph and Raveau B $1985 \mathrm{~J}$. Solid State Chem. 5641

Gross E B, Wainwright J E N and Evans B W 1965 Am. Mineral. 501164

Groult D, Chailleux J M, Choisnet J and Raveau B 1976 J. Solid State. Chem. 19235

Hagman L and Kierkegaard P 1968 Acta Chem. Scand. 221822

Hervieu M, Domenges B and Raveau B 1985 J. Solid Stcte Chem. 58233

Hervieu M and Raveau B 1982 J. Solid State Chem. 43299

Hervieu M and Raveau B 1983 Chem. Scr. 22 117, 223

Kierkegaard P 1962 Ark. Kemi 18553

Kihlborg L 1963 Ark. Kemi 21365

Labbe Ph, Ouachee D, Goreaud M and Raveau B 1983 J. Solid State Chem. 50163

Leclajre A, Borel M M, Grandin A and Raveau B 1985a Mater. Chem. Phys. 12537

Leclaire A, Chahboun H, Grouit D and Raveau B 1986 (to be published)

Leclaire A, Monier J C and Raveau B $1983 \mathrm{~J}$. Salid State Chem. $\mathbf{4 8} 147$

Leclaire A, Monier J C and Raveau B 1984 Acta Cryst. B40 180 
Loclaire A, Monier J C and Raveau B 1985b J. Solid State Chem. 59301 Lloyd D J, Grey I E and Bursill L A 1976 Acta Cryst. B32 1756

Magneli A 1948 Acta Chem. Scand. 2861

Maksimov B A, Litvin B N, Ilyukhin V and Belov N V 1969 Sov. Phys. Crystallogr. 14407

Maksimov B A, Kharitonov Y A and Belov N V 1974 Sov. Phys. Dokl. 18763

Maksimov B A, Demyanets L N, Ilyukhin V and Kharitonov Y A 1975 Acta Crystallogr. 31576

Masse R, Averbuch-Pouchot M T and Durif A $1985 \mathrm{~J}$. Solid State Chem. 58157

Middlemis N 1978 Ph.D. thesis, MacMaster University

Myashiro A 1956 Am. Mineral. 41104

Nguyen N, Choisnet J and Raveau B 1980 J. Solid State Chem. 341

Nguyen N, Studer F, Groult D, Choisnet J and Raveau B 1976 J. Solld State Chem. 19369

Olsen E and Bunch T E $1970 \mathrm{Am}$. Mineral. 55875

Puscharovskii D V, Baataryn T, Pobedimskaya E A and Belov N V 1972 Sov. Phys. Crystallogr. 16628

Raveau B 1979 Rev. Inorg. Chem. 181

Robbins C R and Levin E M 1961 J. Res. Natl. Bur. Stand. A65 127

Roedder E W 1951 Am. J. Sci. 249774

Seifert F and Schreyer W 1967 Contrib. Mineral. Petrol. 14343

Seifert F and Schreyer W 1969 Contrib. Mineral. Petrol. 22190

Shannon R D and Katz L 1970a Acta Cryst. B26 105

Shannon R D and Katz L 1970 b J. Solid State Chem. 1399

Shannon R D, Taylor B E, Gier T E, Chen H Y and Berzins T 1978 Inorg. Chem. 17958

Stone G G and Bursill L A 1977 Philos. Mag. 351397

Studer F and Raveau B 1978 Phys. Status Solidi A48 301 